\title{
Contributions of Light Microscopy to Contemporary Materials Characterization: The New Directional Solidification
}

\author{
Lawrence E. Murr • Edwin Martinez • \\ Sara M. Gaytan • Diana A. Ramirez
}

Received: 10 November 2011/ Accepted: 15 December 2011/Published online: 28 February 2012

(C) Springer Science+Business Media, LLC and ASM International 2012

\begin{abstract}
In this article, we illustrate novel, columnar precipitate architectures in Co-base and Ni-base superalloys, and $\mathrm{Cu}$ components, directionally fabricated by electron beam melting; using light microscopy (LM). These microstructural architectures and related microstructural features are characteristic of a new directional solidification phenomenon created by selective melting of precursor powder layers, forming 3-dimensional (3D) products which result by additive manufacturing. Comprehensive, micron-scale observations rendered in $3 \mathrm{D}$ metallography are supplemented by transmission electron microscopy and scanning electron microscopy to provide a structural and microstructural overview. These observations illustrate the continuing importance of LM in contemporary materials characterization applied to advanced metals technologies.
\end{abstract}

Keywords Electron beam melting · Superalloys · Copper · Directional solidification $\cdot$ Light microscopy $\cdot$ Electron microscopy

\section{Introduction}

In the general transition from the liquid (melt) to the solid state (or phase), the solid phase must have a lower free energy than the liquid at temperatures below the melting point, while the liquid phase free energy must be lower above the melting point. By definition, the melting point is the temperature at which the free energies for the solid and

L. E. Murr $(\bowtie)$ - E. Martinez - S. M. Gaytan - D. A. Ramirez Department of Metallurgical and Materials Engineering, The University of Texas at El Paso, El Paso, TX 79968, USA e-mail: lemurr@utep.edu the liquid phases are equal, and these phases can co-exist in equilibrium. During solidification, the liquid immediately in front of the interface is actually at a temperature below the equilibrium liquids temperature and is therefore supercooled. This is termed constitutional supercooling since it arises from a composition change rather than a temperature change. Solidification perpendicular to a plane solid-liquid interface (or solidification front) is considered directional and is ideally characteristic of single-crystal growth for a single-phase (composition) system. This can be achieved by pulling solid, oriented seed crystals from the melt or by cooling molten material by moving it through a temperature gradient in a furnace. Classical crystal growth techniques achieving these phenomena have included the Czochralski method, originated around 1917 [1], and the Bridgeman method, originated around 1925 [2]. Over the nearly one hundred years since these directional growth methods were developed, there have been extraordinary advances in directional growth and solidification as well as the development of a fundamental understanding of this phenomenon [3-10].

Aside from the directional solidification associated with a planar solid-liquid interface, it is almost intuitive that any perturbation or protuberance at this interface would result in some growth variance. This could be induced by a defect (impurity inclusion), variation in composition, or variations in the thermal gradient. Dendritic solidification in its various forms is perhaps the most notable of these solidification phenomena, and is often a consequence of rapid solidification, especially involving small volume regimes such as liquid spheres rapidly solidifying in atomization processes to produce spherical metal powders [11, 12].

In addition to crystal growth or directional, multi-crystal (or cellular grain) solidification, and dendritic (or unidirectional) solidification, directional solidification also 
involves simple binary eutectics. As shown schematically in Fig. 1, solid phases $\alpha$ and $\beta$, as represented in the binary eutectic phase diagram, simultaneously solidify from the liquid, $L$. Solidification in the direction of the arrow creates an aligned, two-phase solid. This two-phase, unidirectional, eutectic composite can be lamellar or rod (fiber) form depending on the growth conditions and total free energy minimization, which generally drives the lamellar-to-rod transition implicit in the schematic sequence shown in Fig. 1. The major solidification parameters involve the thermal gradient at the liquid/solid interface and the growth or solidification rate, $R$, or the velocity at which the liquid/ solid interface advances. Jackson and Hunt [13] have shown that the type of $\alpha / \beta$ phase morphology (Fig. 1) either lamellar or rod-will depend upon the relative volume fraction of each phase. It is known that the rod morphology prevails when one phase is present in amounts less than $1 / \pi$ of the total volume. The volume fraction of each phase is determined from the phase diagram (Fig. 1). Recognizing that the phase morphology is controlled by the relative volume fraction as noted, Tiller [14] showed that the spacing of the interpenetrating phases, $\lambda$, in Fig. 1, was controlled by the liquid/solid interface velocity or

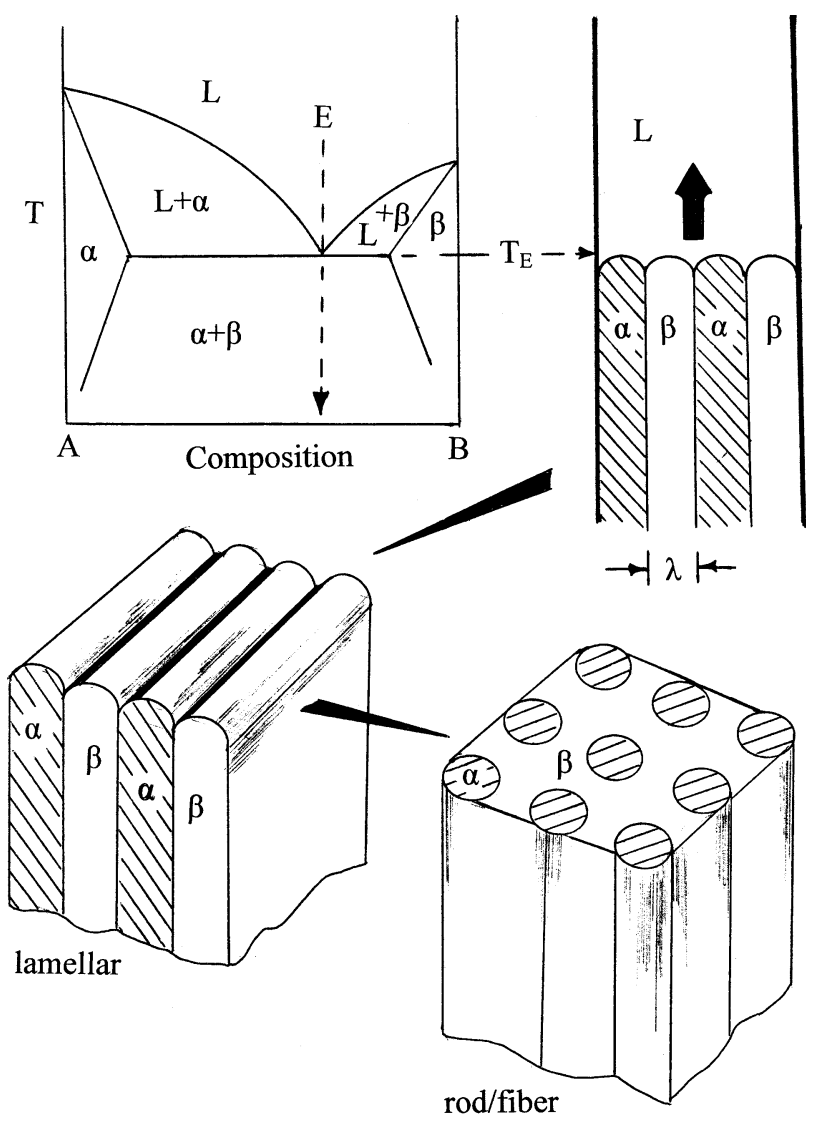

Fig. 1 Eutectic phase diagram (left) and associated unidirectional eutectic phase solidification schematics. Liquid, $L$; solid phases $\alpha$ and $\beta . T_{\mathrm{E}}$ is the eutectic $(E)$ invariant point temperature solidification rate, $R: \lambda^{2} R=$ constant. Consequently, the lamellar or rod spacing, $\lambda$, in Fig. 1 decreases with increasing solidification rate.

Eutectic alloys with fibrous (rod-like) or lamellar structures, as illustrated schematically in Fig. 1, provide unique strengthening or aligned, reinforced composite design concepts. The first such system to behave mechanically as a composite, with significant reinforcement of the matrix, was the $\mathrm{Al}-\mathrm{Al}_{3} \mathrm{Ni}$ system where the aligned $\mathrm{Al}_{3} \mathrm{Ni}$ fibers comprised 11 vol.\% [15]. In this system, the aligned strength was roughly four times that for the conventionally cast eutectic material. These concepts led to directional solidification innovations applied to turbine blade development involving eutectic superalloys, notably Ni-base superalloy compositions [16, 17]. These have included precipitation-reinforced eutectic superalloys [18].

The schematic views of directional solidified phase structures in Fig. 1 have of course been observed by light microscopy (LM) as illustrated typically in Fig. 2, which provides recognizable contrast without etching, following the pioneering application of LM by Sorby [19] more than a century ago. The most prominent two-phase image features observed by Sorby [19] with only surface polishing were those for iron-rich meteorites.

Figure 2 not only illustrates the realities of directional eutectic solidification as described above and shown schematically in Fig. 1 but also provides a reference point for more conventional directional solidification in contrast to the directional solidification associated with laser and electron beam melting (EBM) and powder layer solidification. These newer fabrication technologies, employing metal or alloy powders, create 3D monolithic components by additive (layer) manufacturing (AM). In these

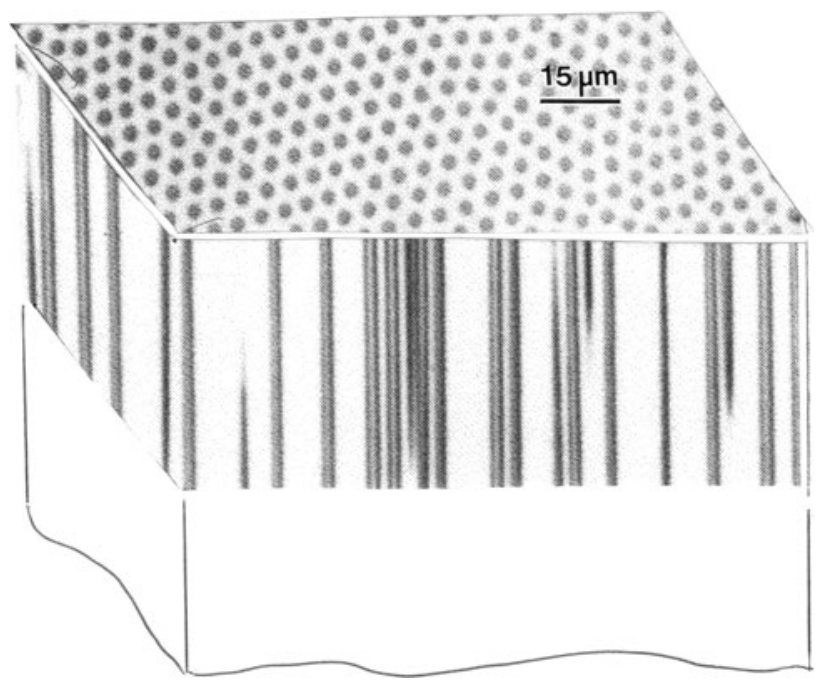

Fig. 2 Fibrous (dark rod phase) eutectic (MnSb) in $\mathrm{Sb}$ matrix shown in 3D composition of light microscope images for as-polished unidirectionally solidified casting. After Kraft [20] 
processes, a laser or electron beam is scanned over each successive layer to selectively melt specific regions directed by a CAD model.

In this presentation, we describe novel microstructural features which are unique to EBM of a range of precursor metal or alloy powders. LM, augmented by scanning and transmission electron microscopy (SEM and TEM), provide comprehensive materials characterization for these new directional solidification prototypes.

\section{An Overview of EBM}

Figure 3 shows a schematic view of an EBM system (Arcam A2) which is ideally an adaptation of an electron optical system [22] similar in concept to a scanning electron microscope (SEM) and an EBM unit. The electron optical column (1-3 in Fig. 3) generates an electron beam at $60 \mathrm{kV}$ accelerating potential at beam currents ranging

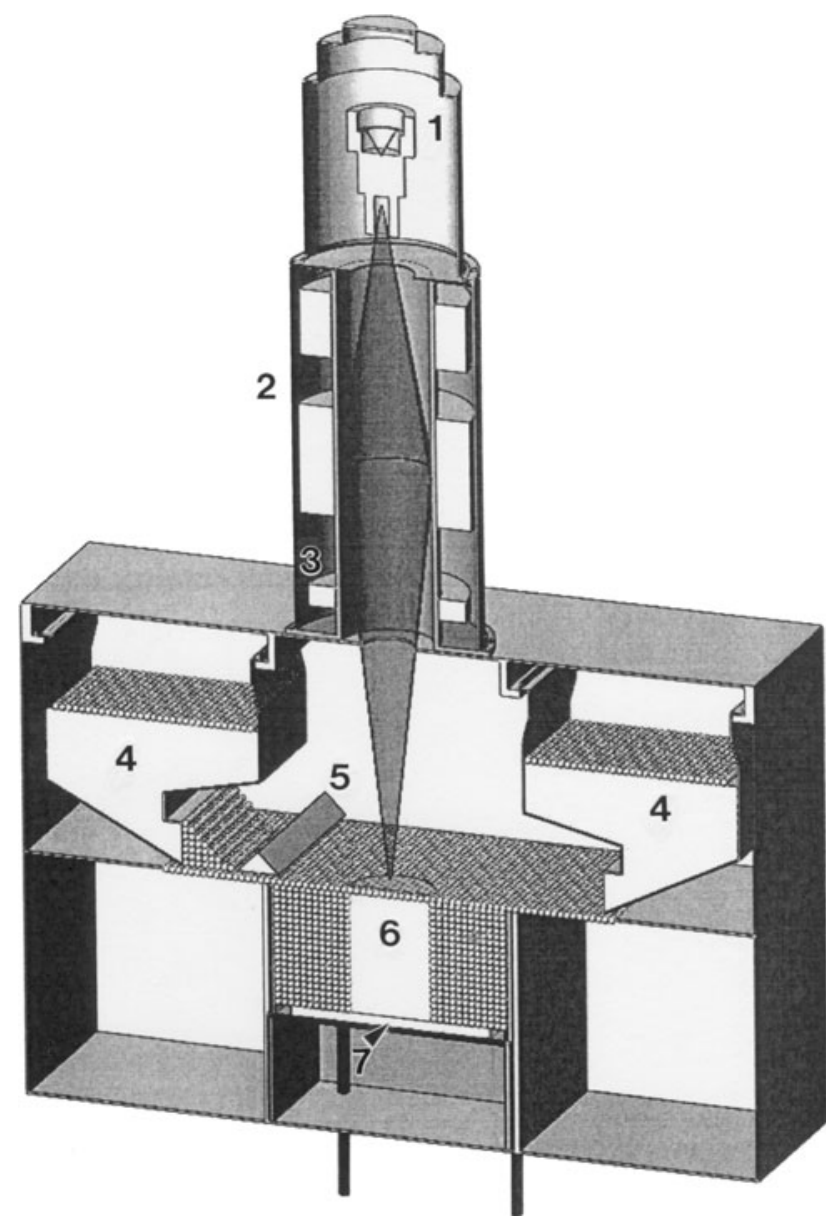

Fig. 3 Schematic view of Arcam A2 electron beam melting system. Electron gun (1); focusing lens (2); beam scan coils (3); powder cassettes (4); layer rake (5); building specimen (6); build table (7). After Murr et al. [21] from a few milliamperes to $>30 \mathrm{~mA}$. Scan coils similar to those in a conventional SEM scan the focused beam across a freshly raked (5) powder layer, with metal or alloy powder gravity fed from cassettes at (4) in Fig. 3. The beam is initially rastered at very high speeds $\left(\sim 10^{4} \mathrm{~mm} / \mathrm{s}\right)$ in multiple passes to preheat the layer; followed by a melt scan at $\sim 10^{2} \mathrm{~mm} / \mathrm{s}$ and at reduced beam current. The beam scanning (and melt) is directed by a CAD model developed to allow complex, 3D components to be fabricated layerby-layer (AM). As the beam is rastered in the melt scan in directions perpendicular to one another $(x, y)$, the selected area of powdered material melts in small, interconnected liquid pools, which rapidly cool and solidify with a plane or cellular solid/liquid interface; characteristic of the directional solidification is shown schematically in Fig. 1. Ideally, each layer is melted and the building solid component (6) moves downward as shown at (7) in Fig. 3.

The metal or alloy powders placed in the cassettes in the EBM system shown in Fig. 3 are normally atomized, rapidly solidified, pre-alloyed powders. These have distribution of spherical particle sizes as illustrated in Fig. 4 which compares a Co-base and a Ni-base superalloy powder.

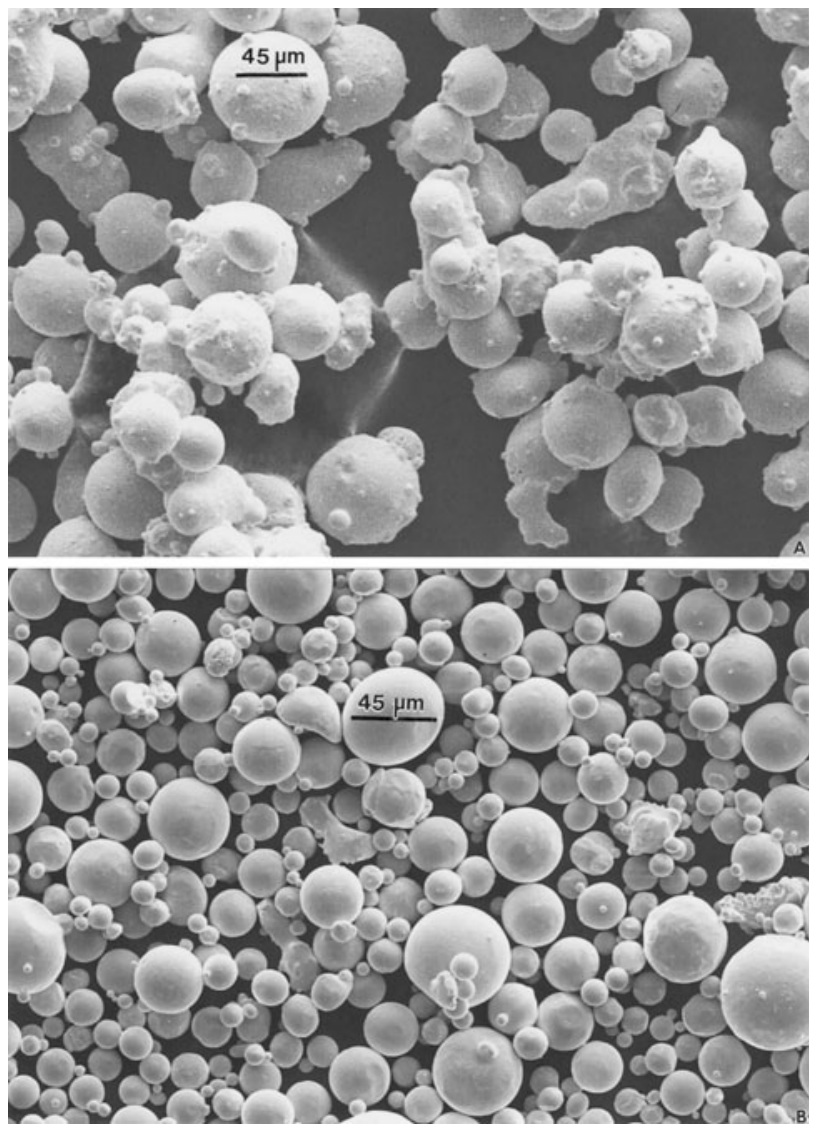

Fig. 4 Pre-alloyed, atomized, rapidly solidified powders observed in the SEM. a Co-29Cr-6Mo-0.22 C powder and b Ni-21CR-9Mo- $4 \mathrm{Nb}$ 


\section{Fabrication of Co-Base Superalloy Components by EBM}

Figure 5 shows a LM isometric projection representing a section of an EBM fabricated cylinder shown schematically in Fig. 3 (at 6). There is a striking similarity to the LM image for the unidirectionally solidified MnSb eutectic casting in Fig. 2. However, unlike Fig. 2, the LM image in Fig. 5 was polished and etched (using a 6:1 solution of $\mathrm{HCl}: \mathrm{H}_{2} \mathrm{O}_{2}(3 \%)$ for $16 \mathrm{~h}$ at room temperature). Figure 5 illustrates some large, directional (textured) fcc grains indicated by $\mathrm{G}$, as well as some irregular, elongated (directional) grains and columns of precipitates. The more regular precipitate columns occupying the front face (of the composition) in Fig. 5 represent discontinuous columns of $\mathrm{Cr}_{23} \mathrm{C}_{6}$ carbides which have been rigorously identified by Gaytan et al. [23], utilizing SEM, TEM (including selectedarea electron diffraction), and x-ray diffraction (XRD) spectrometry.

While in Fig. 5 there is some indication of carbide precipitate segregation to the columnar (directional) grain boundaries, large segments of the microstructure are characterized by discontinuous precipitate columns whose

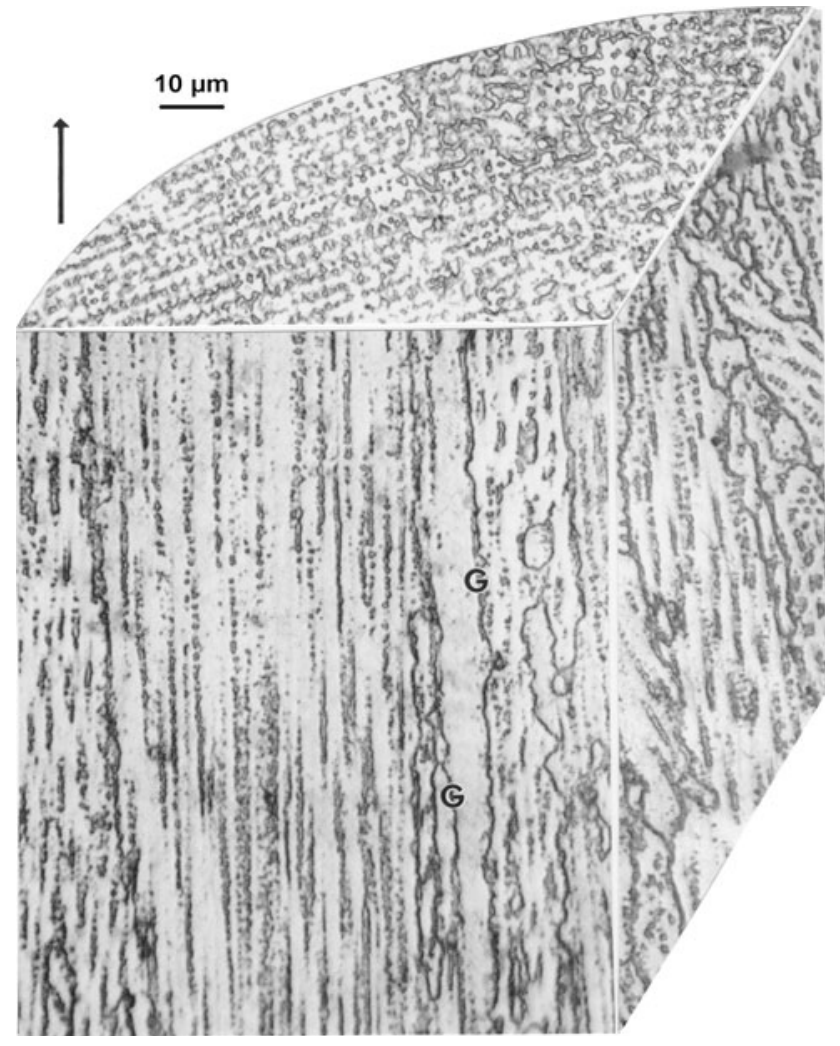

Fig. 5 3D-LM image composite showing representative section of EBM fabricated cylinder of $\mathrm{Co}-\mathrm{Cr}$ powder in Fig. 4(a). The arrow in upper left indicates the build (solidification) direction. $G$ represents columnar-directional grains regularity extends several hundred microns, and whose spacing, especially notable in the transverse (horizontal plane) image in Fig. 5, is $\sim 2 \mu \mathrm{m}$. This represents the approximate dimension of spatial $x-y$ melt scans or melt pool development in the powder layer represented schematically in Fig. 6. The $x-y$ scanning within the same spatial array in the powder layer also characterizes multiple pre-heat scans $(p(x)$ and $p(y)$ in Fig. 6). These pre-heat and melt scans $(m(x)$ and $m(y)$ in Fig. 6) produce the thermal gradient and solidification velocity, which in turn are determined by the scanning beam parameters (primarily beam focus, beam current, and scan speed). These have also been referred to as a scan strategy in the laser-beam fabrication of Ti-6Al-4V components by selective laser melting (SLM) [24].

Because the melt ideally occurs in spatial pools $(\sim 2 \mu \mathrm{m})$ in each layer (Fig. 6), small variations in beam parameters, including scan precision, beam voltage and current, the efficiency of precipitate-column development is often interrupted as illustrated in Fig. 6, and this can include the continuity or segregation of precipitates in each column. This feature is illustrated in more detail in Figs. 7 and 8 , which show a low magnification and higher magnification views of the longitudinal (vertical plane) section parallel to the build direction shown by the arrow. Figure 8 also shows columnar grains and precipitate segregation at

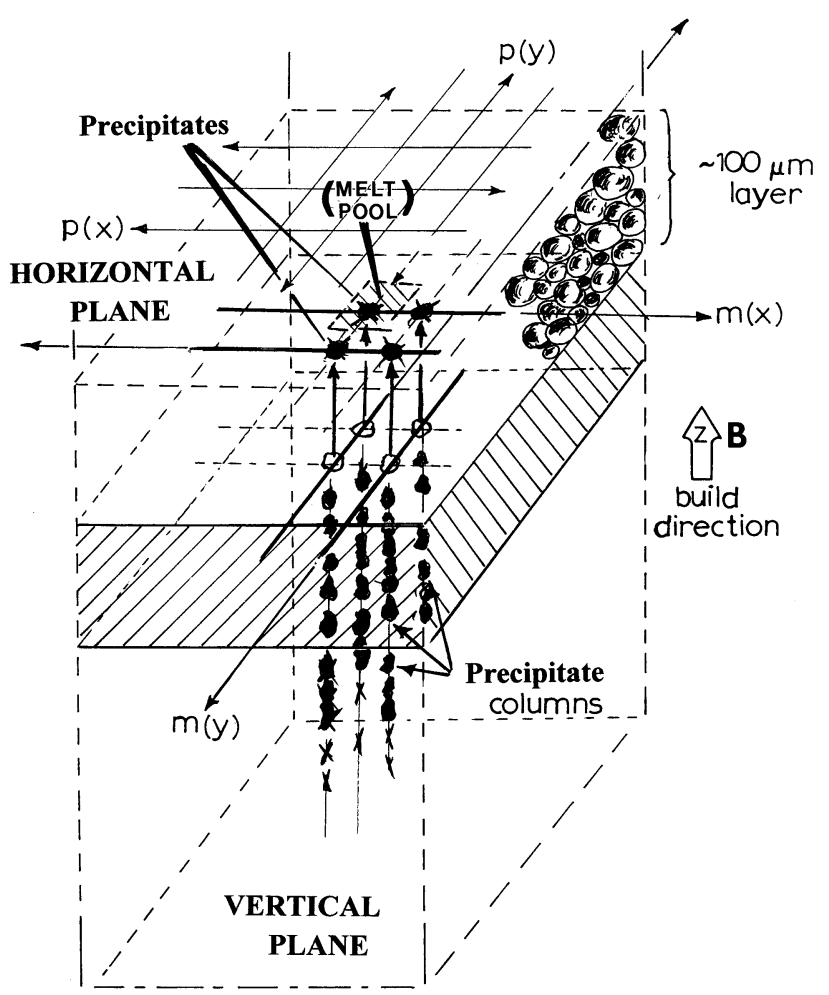

Fig. 6 Schematic representation for development of columnar carbides in EBM fabrication of Co-base superalloy components as observed in Fig. 5. After Gatan et al. [23] 


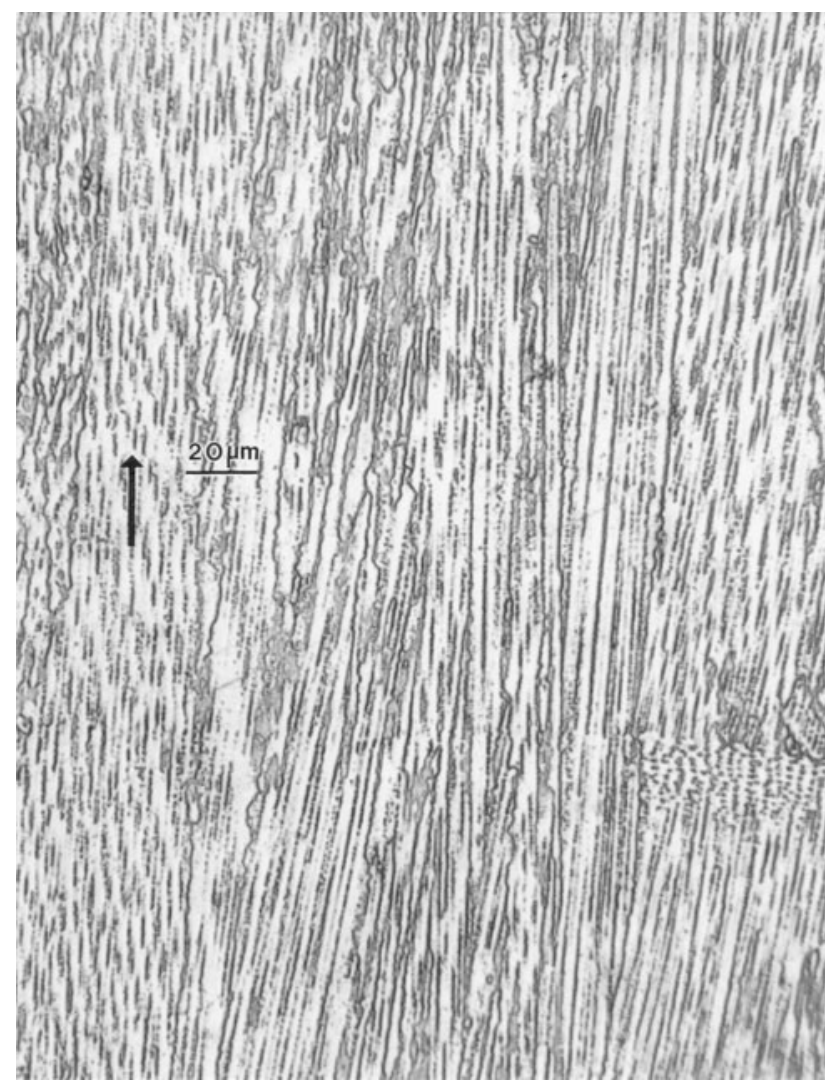

Fig. 7 Low magnification (LM) image in the longitudinal (vertical plane) section characteristic of Fig. 5 showing carbide columns within columnar grains, some extending $>0.2 \mathrm{~mm}(200 \mu \mathrm{m})$

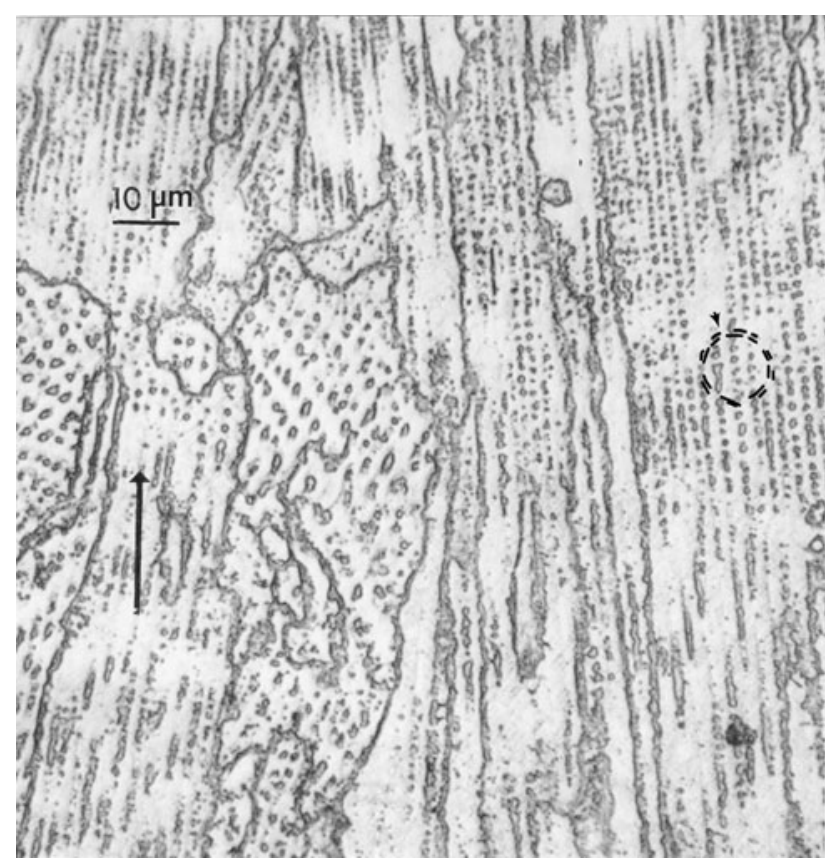

Fig. 8 Higher magnification (LM) image showing columnar grains, grain boundary precipitate segregation, and variations in regular precipitate columns characteristic of Figs. 5 and 7. Circled area indicates typical $\mathrm{Cr}_{23} \mathrm{C}_{6}$ particles these columnar grain boundaries as described for Fig. 5, along with examples of carbide precipitate distribution (or density) represented in the columnar features. These features ideally represent a precipitate (microstructural) columnar architecture.

Figure 9(a) and (b) shows a low and higher magnification views, respectively, of the cubic (fcc: $a=10.7 \AA$ ) $\mathrm{Cr}_{23} \mathrm{C}_{6}$ precipitate particles composing the columnar architectures shown in LM views of Figs. 5 to 8; especially a region characterized by the circled zone in Fig. 8. It can be noted in Fig. 9 that the precipitates are oriented in the same crystallographic, coincident directions, representing $\{100\}$ coincidence of the fcc carbide precipitates with the fcc Co-Cr matrix $(a=3.6 \AA)$ : $\{100\} \mathrm{Cr}_{23} \mathrm{C}_{6} \|\{100\}$ $\mathrm{Co}-\mathrm{Cr}$.

The power of LM, in the context of materials characterization in a broad sense, and from a contemporary perspective, is implicit on comparing Fig. 2 with Figs. 5, 7, and 8. In this respect, the limitations of light microscopy in materials characterization are also implicit, although there are interesting consequences on comparing image features apparent without etching in Fig. 2, in contrast to more conventional metallographic etching shown in Figs. 5, 7, and 8 . Etchants are either selectively reactive in different grain orientations, at grain boundaries (especially having different interfacial free energies [25]) or at different phases, especially precipitates. Consequently, etchants
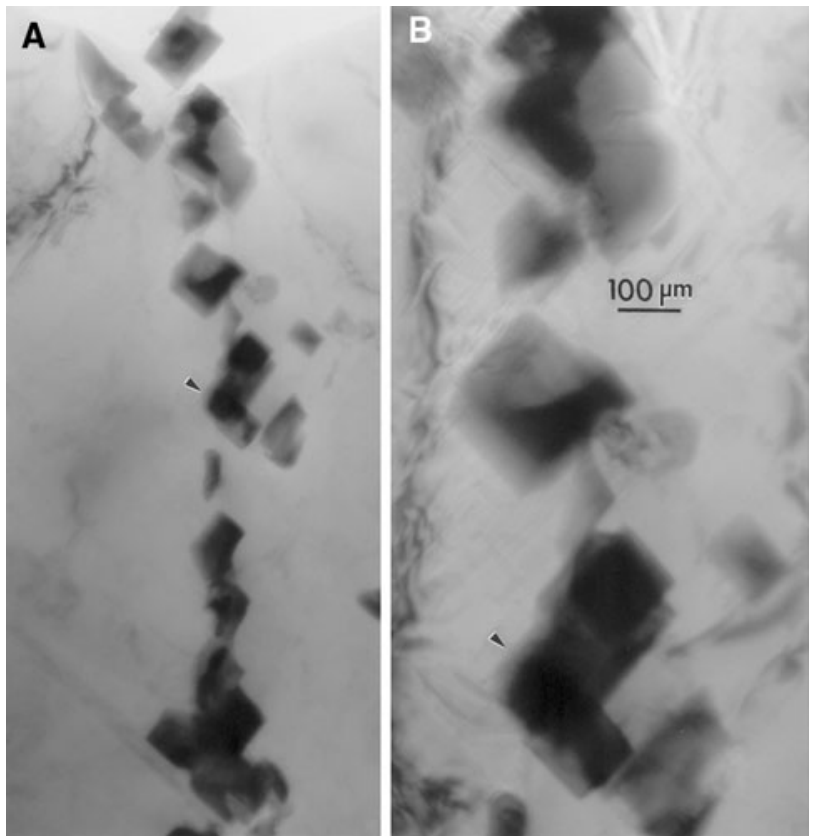

Fig. 9 TEM bright-field images of $\mathrm{Cr}_{23} \mathrm{C}_{6}$ (cubic) precipitates composing columnar architectures represented within the circled area in Fig. 8. a Low-magnification image. b Higher magnification image of same region in (a). The arrow represents $\langle 100\rangle$ directions in the Co-Cr fcc matrix 
produce contrast by specular reflection variations or selective absorption at etched features. While etching allows for contrast and shape recognition, there is no mechanism for elemental analysis (composition) and rarely crystallographic characterization. Correspondingly, as illustrated by comparing Figs. 5, 7, and 8 with Fig. 9, LM imaging details are complemented by TEM. However, metallography involving etchant-induced contrast can differentiate relative crystallographic orientation differences as well as boundary energetics.

For example, when the EBM-fabricated components represented by Figs. 5 and 7 to 9 were Hot Isostatically Press (HIP)-annealed (at $1200{ }^{\circ} \mathrm{C}$ for $4 \mathrm{~h}$ and homogenized at $1220{ }^{\circ} \mathrm{C}$ for $4 \mathrm{~h}$ ), the $\mathrm{Cr}_{23} \mathrm{C}_{6}$ precipitates and precipitate columns dissolved as the columnar grain structure recrystallized and grains become equiaxed. In addition, these generally equiaxed grains contained annealing twins because the fcc $\mathrm{Co}-\mathrm{Cr}$ matrix exhibited a twin-boundary free energy of only about $30 \mathrm{~mJ} / \mathrm{m}^{2}$ [25]; in contrast to grain boundary free energies averaging $600 \mathrm{~mJ} / \mathrm{m}^{2}$ [25]. These features are illustrated in the LM image in Fig. 10(a) which exhibits limited grain contrast, but notable grain boundary etching. This etching at the grain boundaries can be enhanced by altering the etchant conditions as illustrated in Fig. 10(b) which shows only segments of grain boundaries in some cases, but no twin boundary etching. This occurs because $\mathrm{Cr}_{23} \mathrm{C}_{6}$ precipitates do not form in the coherent twin boundaries within the annealing treatment, and grain boundaries with energies below some threshold for carbide nucleation also have limited precipitation [26]. What is not apparent in Fig. 10 is the fact that the HIP-annealed $\mathrm{Co}-\mathrm{Cr}$ alloy microstructure contains moderate to dense intrinsic stacking faults because, like the coherent twin boundaries, the interfacial free energy is low $\left(\sim 15 \mathrm{~mJ} / \mathrm{m}^{2}\right.$ for the stacking faults [26]). This feature requires TEM image augmentation corresponding to the characterization of the EBM-fabricated carbide column architectures shown in Figs. 5 and 7 to 9. While the comparison of Figs. 10(a) and 8 provides dramatic evidence for microstructural variations, the same is true on comparing Figs. 9 and 11; but on different diagnostic levels and at different resolutions.

\section{Fabrication of Ni-Base Superalloy Components by EBM}

Figure 12 shows magnified Ni-base (alloy 625) superalloy powders as in Fig. 4(b), which, especially in the magnified image of Fig. 12(b) show a dendritic structure characteristic of these rapidly solidified alloys [27]. These features are also illustrated in the LM polished and etched powder sections shown in Fig. 13 at a magnification corresponding to that in Fig. 12(b).
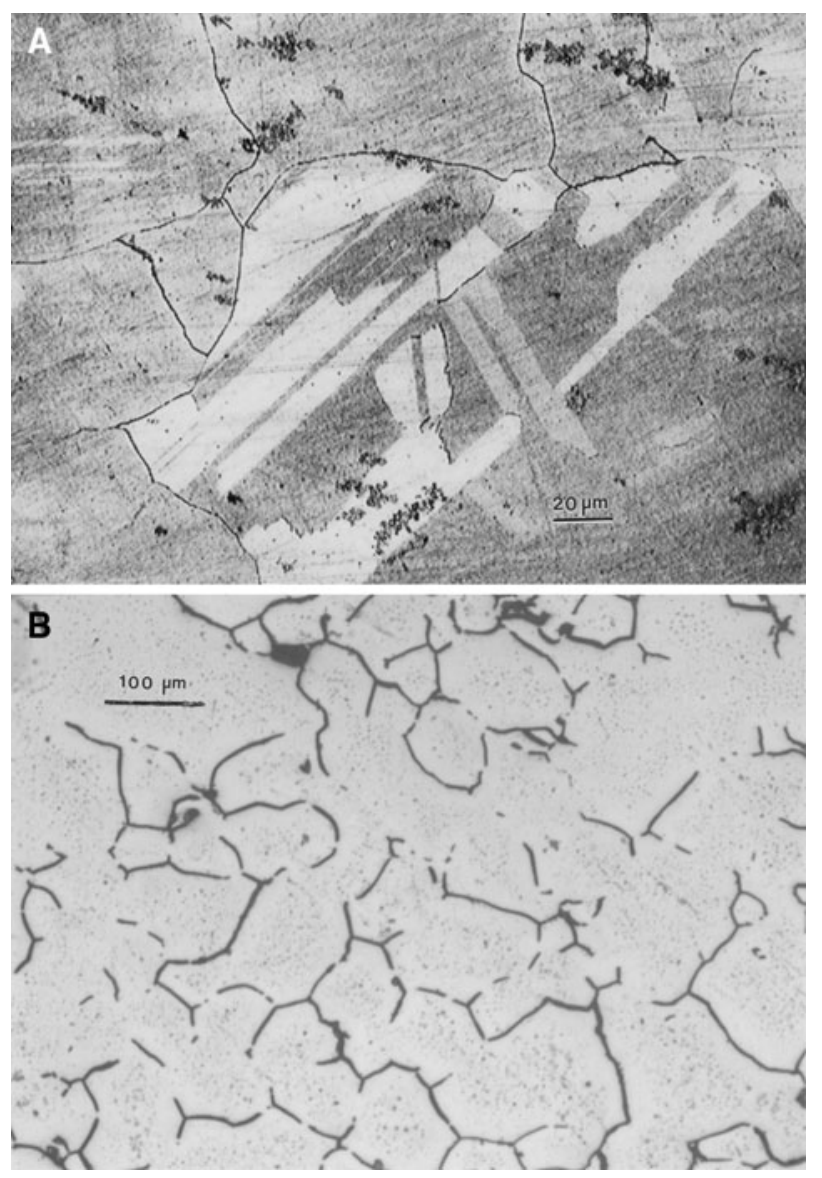

Fig. 10 LM images for EBM-fabricated Co-Cr alloy following HIPanneal. a Equiaxed grain structure containing coherent annealing twin boundaries. Etchant: 6:1 $\mathrm{HCl}: \mathrm{H}_{2} \mathrm{O}_{2}(3 \%)$ for 1-2 min. b Exaggerated etching of microstructure in (a) at a lower magnification using a different etchant $\left(100 \mathrm{~mL} \mathrm{H}_{2} \mathrm{O}, 50 \mathrm{~mL} \mathrm{HCl}, 10 \mathrm{~mL} \mathrm{HNO}_{3}\right.$, and $10 \mathrm{~g}$ $\mathrm{FeCl}_{2}$ for 1-2 min.) to highlight $\mathrm{Cr}_{23} \mathrm{C}_{6}$ precipitation in high-energy grain boundary segments

In contrast to the dendritic structure shown for the $\mathrm{Ni}-21 \mathrm{Cr}-9 \mathrm{Mo}-4 \mathrm{Nb}$ powder in Fig. 13, Fig. 14 shows an $\mathrm{LM}$, isometric view representing a section of an EBM fabricated cylinder of this powder. The columnar architecture characteristic of this section is remarkably similar to that for EBM fabricated $\mathrm{Co}-29 \mathrm{Cr}-6 \mathrm{Mo}-0.22 \mathrm{C}$ cylindrical section shown in Fig. 5, where the columnar microstructure is characterized by discontinuous $\mathrm{Cr}_{23} \mathrm{C}_{6}$ cubic precipitates having a crystallographic coincidence with the fcc Co-Cr matrix ((100) $\left.\mathrm{Cr}_{23} \mathrm{C}_{6} \|(100) \mathrm{Co}-\mathrm{Cr}\right)$. Even the spacing of the columnar architecture in Fig. 14 is essentially the same as that in Fig. 5. Careful examination and comparison of Figs. 5 and 14 illustrate that the cubic $\mathrm{Cr}_{23} \mathrm{C}_{6}$ precipitates composing the Co-base EBM samples are replaced by $\mathrm{Ni}_{3} \mathrm{Nb}$ (bct: $a=3.6 \AA, c=7.4 \AA$ ) precipitate platelets coincident with the $\mathrm{Ni}-\mathrm{Cr}$ fcc $\{111\}$ planes. These features become somewhat more clarified in the vertical plane (parallel to the EBM build direction) LM 


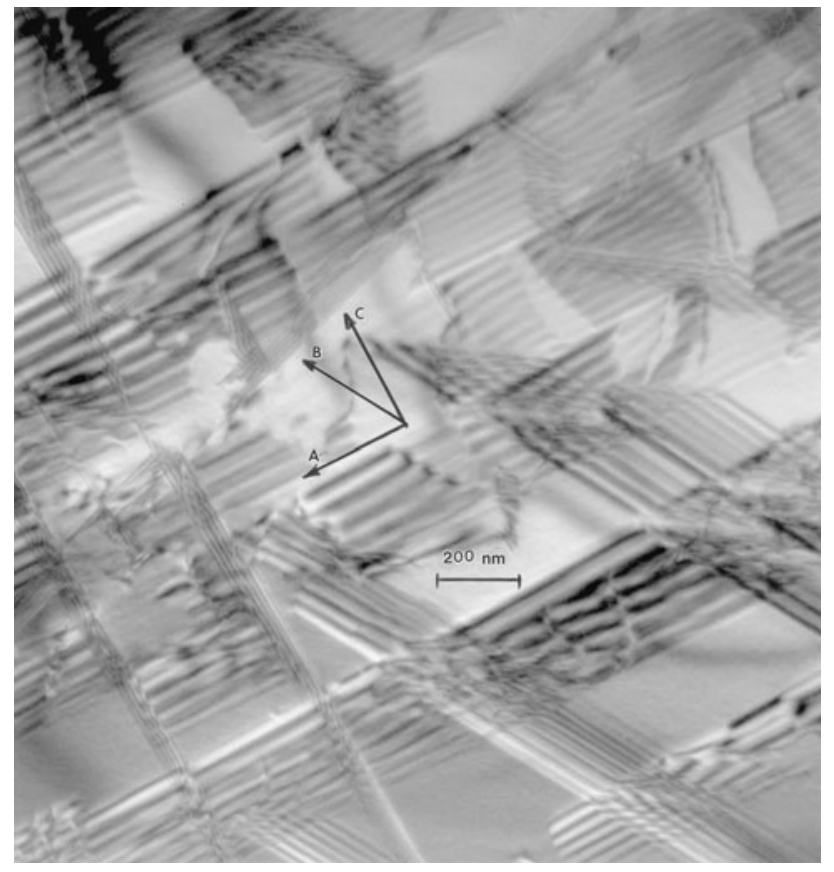

Fig. 11 TEM bright-field image of intrinsic stacking faults in a (123) oriented grain in the structure of Fig. 10(a). Three different sets of stacking faults on $\{111\}$ planes are represented by trace directions $A$, $B$, and $C$ corresponding to trace directions $[\overline{1} 2 \overline{1}],[14 \overline{3}]$, and $[52 \overline{3}]$, respectively

view shown in Fig. 15 and the corresponding SEM backscattered electron image shown in Fig. 16. These two images (Figs. 15, 16) correspond to large, elongated, textured (or directional) grains having a (220) orientation, and giving rise to $\{111\}$ coincident $\mathrm{Ni}_{3} \mathrm{Nb}$ precipitate platelets having the same crystallographic features. These are shown as crystallographic trace directions $a$ and $b$ in Fig. 16, corresponding to $a=1 \overline{1} 2$ and $b=\overline{1} \overline{1} 2$ in a (220) surface plane. The (110) plane coincidence for the vertical plane section in Figs. 15 and 16 has been demonstrated by x-ray diffraction as well as systematic TEM involving both bright- and dark-field imaging, and selected-area electron diffraction [28]. Figure 17 shows a TEM image corresponding to the EBM vertical plane sections in Figs. 15 and 16, and showing the $\mathrm{Ni}_{3} \mathrm{Nb}$ (bct) platelets to be coin-

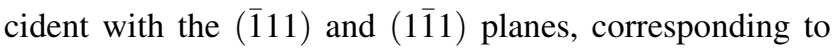
the trace directions shown as $a$ and $b$ in Figs. 16 and 17.

It can be observed in Figs. 14 and 15 that the actual columnar (directional) grains extend over the same length $(\geq 200 \mu \mathrm{m})$, and that the grain width (and equiaxed grain size in the horizontal plane in Fig. 14, which bisects these columnar grains) can vary from a few microns to $>10 \mu \mathrm{m}$.

As in the case for the EBM-fabricated Co-base superalloy represented in Fig. 5, the $\mathrm{Ni}_{3} \mathrm{Nb}$ precipitate columns in the EBM-fabricated Ni-base superalloy in Fig. 14 also dissolved upon high-temperature annealing or HIPannealing at $1120^{\circ} \mathrm{C}$. Simultaneous with the $\mathrm{Ni}_{3} \mathrm{Nb}$
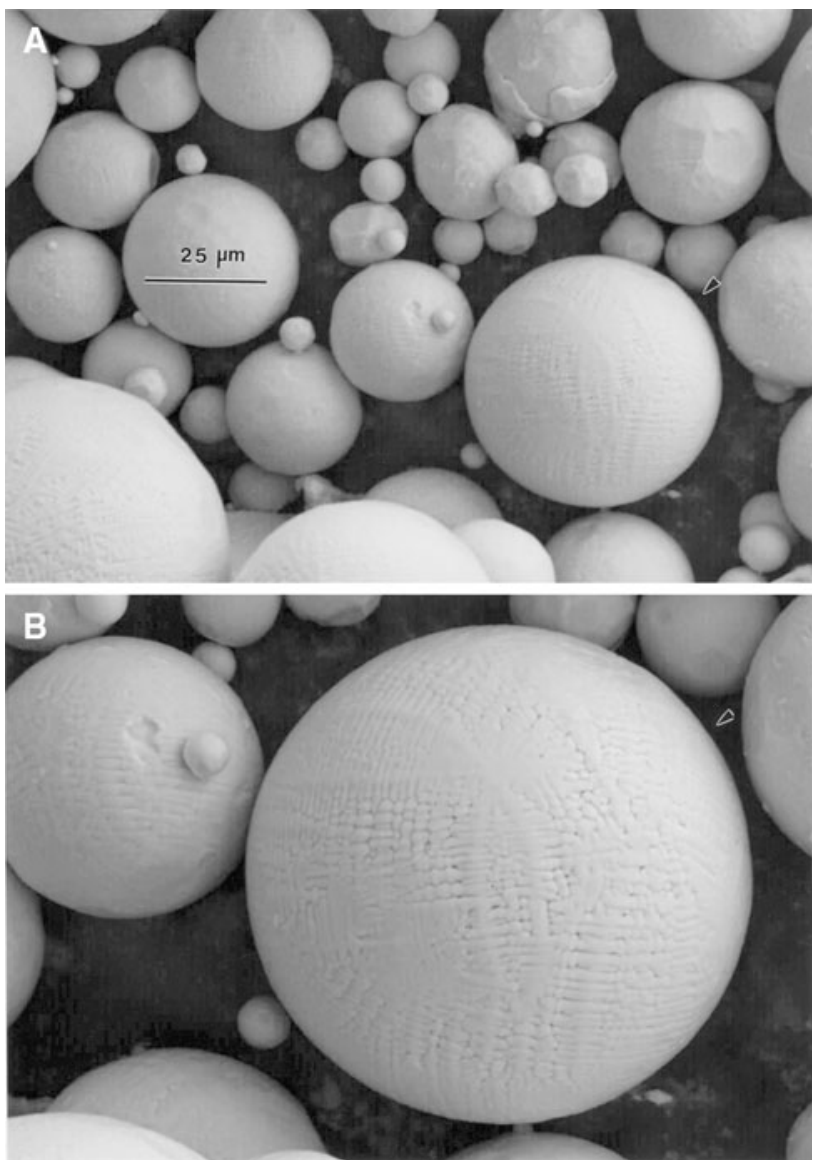

Fig. 12 Magnified SEM images showing dendritic microstructures in the $\mathrm{Ni}-\mathrm{Cr}-\mathrm{Mo}-\mathrm{Nb}$ alloy powders in Fig. 4(b). The arrow shows a common reference point or reference powder particle

precipitate dissolution, the grain columns also recrystallized, forming an equiaxed grain structure containing coherent $\{111\}$ annealing twins very similar to the Co-base superalloy illustrated in Fig. 10(a). This microstructural feature is shown in the isometric view of Fig. 18 which can be viewed in contrast to the as-fabricated EBM columnar architecture shown in Fig. 14. In addition, like the annealing grain structure for the Co-base alloy in Fig. 10, the Ni-base grain structure shown in Fig. 18 shows preferential etching at grain boundary portions but no evidence for etching at the linear, coherent twin boundaries. As noted previously, this is due to the fact that the higher energy grain boundaries or grain boundary portions promote precipitate nucleation and growth, while the correspondingly low energy coherent twin boundaries do not [26]. The lower magnification of the isometric view in Fig. 18 does not permit precipitates to be readily identified, while the higher magnification LM vertical reference plane section in Fig. 19 shows these selective grain boundaries containing large precipitate phases in addition to a homogeneous distribution of regular, spheroidal, or globular 


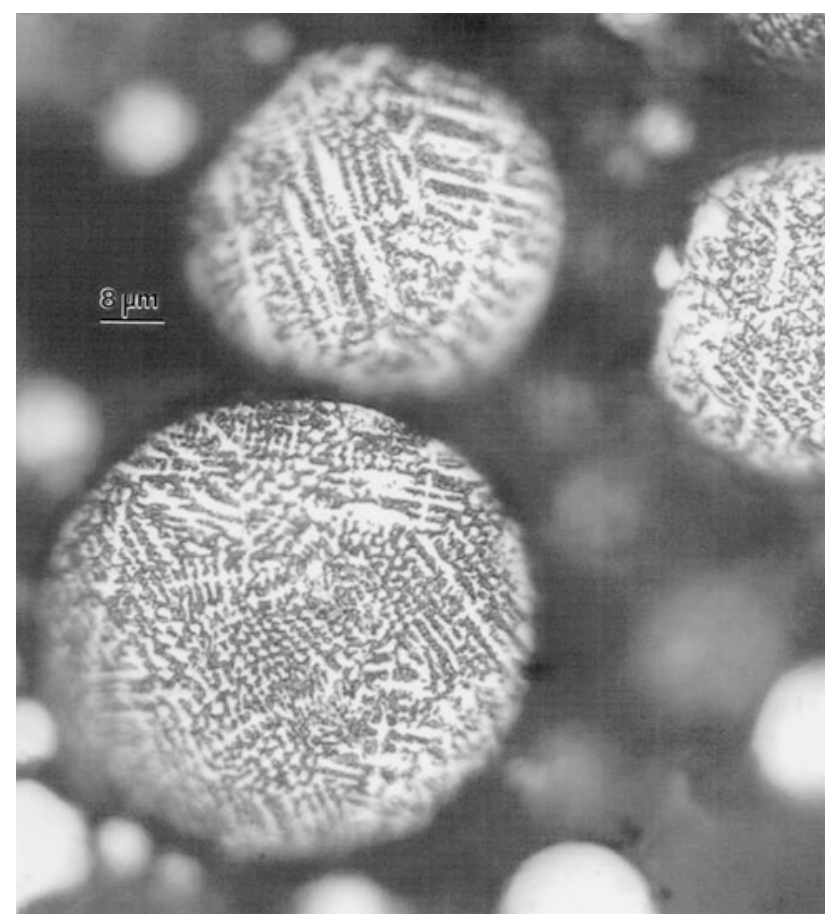

Fig. 13 LM image for polished and etched powder particles as in Fig. 12(b) showing internal particle dendritic structure

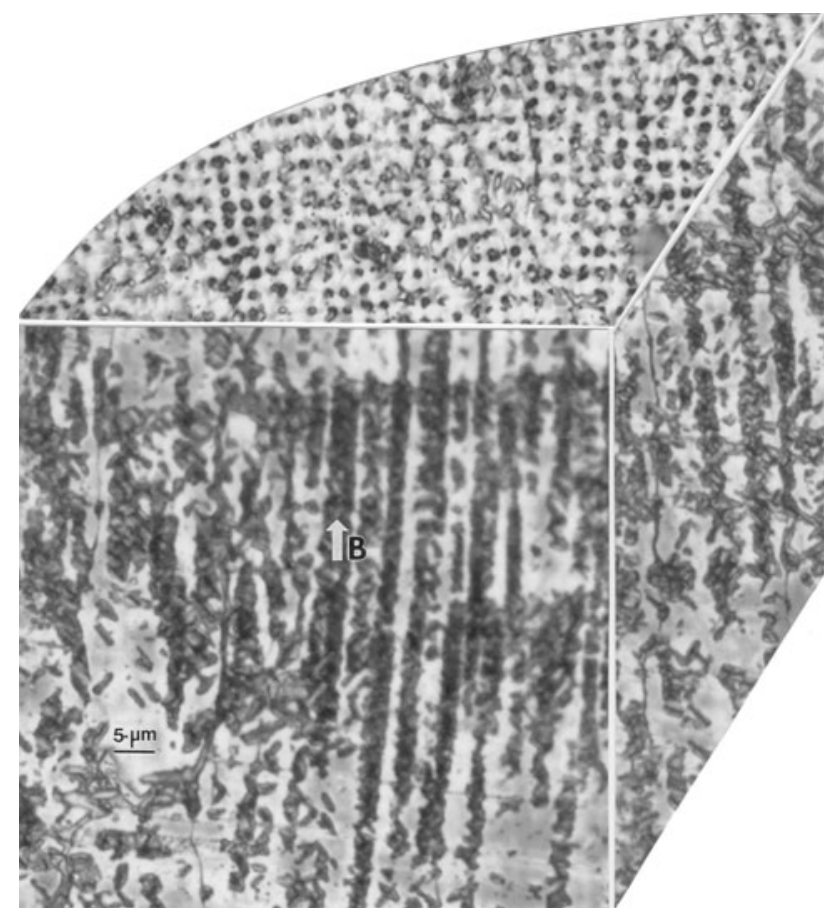

Fig. 14 3D-LM image composite showing columnar precipitate architecture representing a cylindrical EBM component of $\mathrm{Ni}-\mathrm{Cr}-$ $\mathrm{Mo}-\mathrm{Nb}$. The arrow (B) represents the build direction which is parallel to the cylinder axis

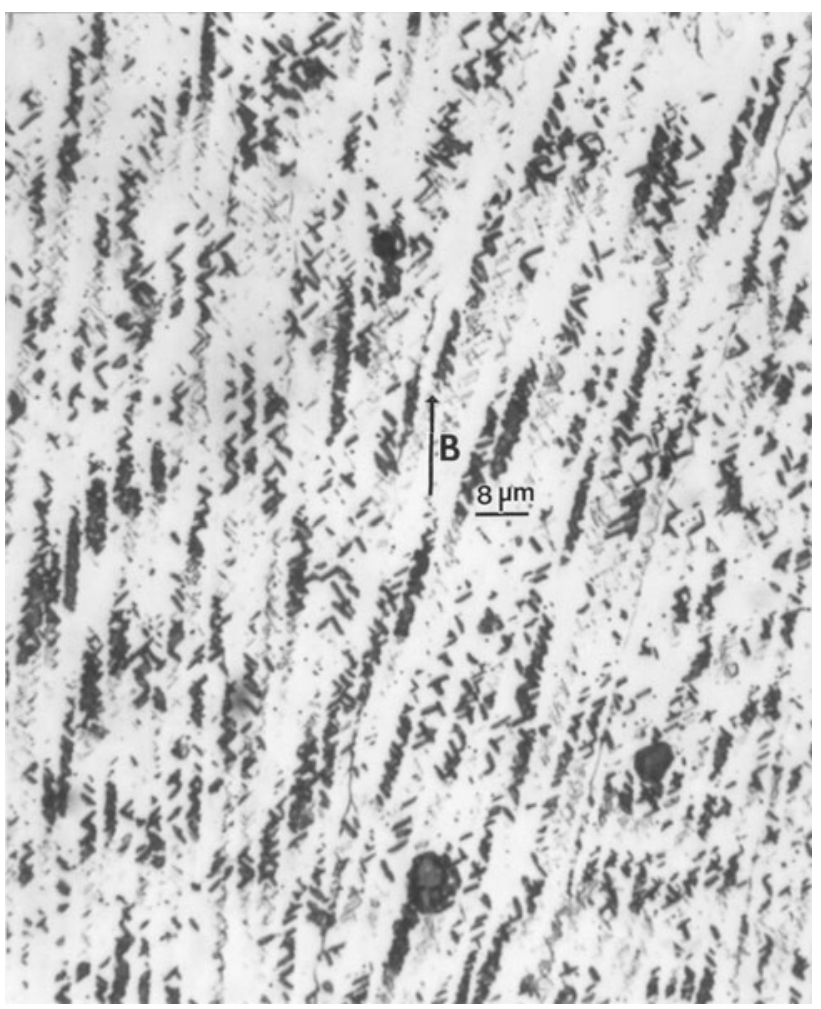

Fig. 15 Finely etched LM image corresponding to a vertical plane section coincident with the build direction in Fig. 14 showing small, crystallographic, planar precipitates. Columnar grains or grain boundaries are also shown. The arrow represents the build direction as in Fig. 14. $B$ indicates build direction

precipitates in the matrix, even within the annealing twin grain interiors. These precipitates have been identified by XRD and selected-area electron diffraction in the TEM to be $\mathrm{NbCr}_{2}$ laves phase (hexagonal: $a=4.9 \AA, c=8.1 \AA$ ) [28]. Similar laves phase precipitates have also been observed in electron beam welded Alloy 718 by Radakrishna et al. [29]. Figure 20 shows a TEM image of globular $\mathrm{NbCr}_{2}$ precipitates corresponding to the LM image areas in Fig. 19.

It should be apparent on comparing Figs. 5 and 14 that the micro-melt directional solidification that creates the precipitate columns in the EBM-fabricated cylinders is the same as shown schematically in Fig. 6, because the electron beam scanning strategy is the same. It should also be apparent that while other analytical or diagnostic tools are required to characterize the chemical nature of precipitates and their crystallographic features, LM, as shown in the isometric views in Figs. 5 and 14, provide a very important, if not the most important perspective. Such has been the nature of LM in metallography since the pioneering period of Sorby [19] more than a century ago. 


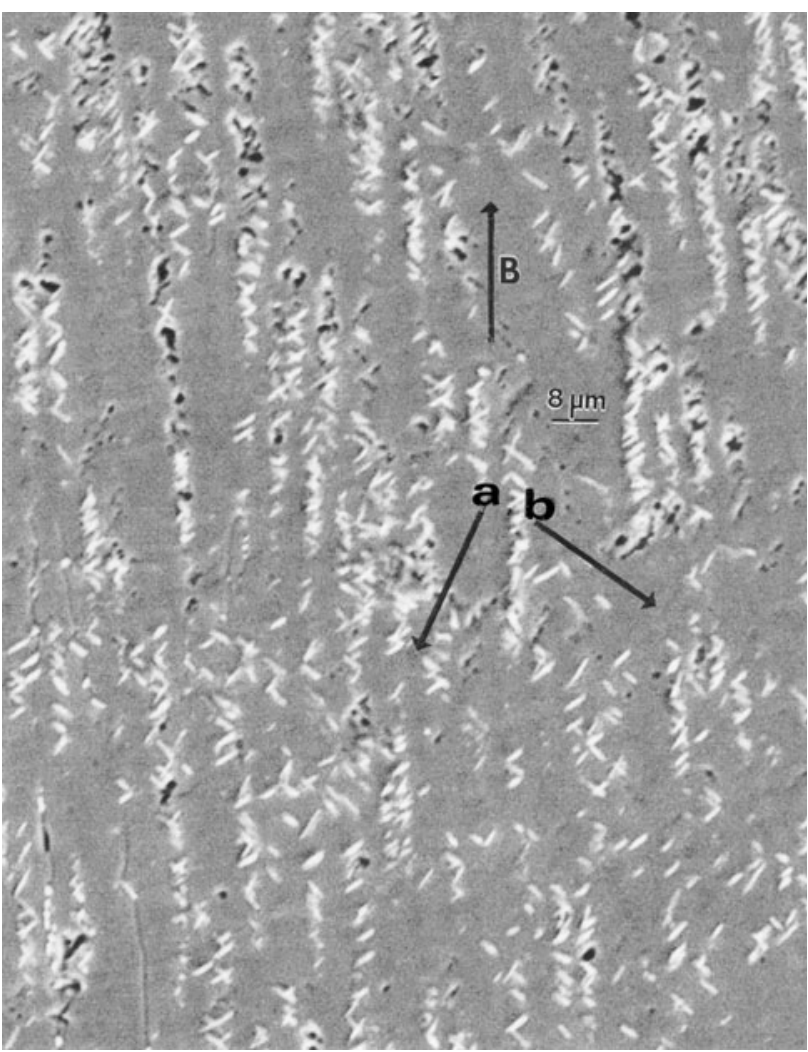

Fig. 16 SEM backscattered electron (BSE) image of a vertical plane section as in Fig. 15 showing BSE contrast between the precipitate columns and the fcc $\mathrm{Ni}-\mathrm{Cr}$ matrix. The planar, $\mathrm{Ni}_{3} \mathrm{Nb}$ precipitate plates are coincident with crystallographic directions $a$ and $b . B$ indicates build direction. Used by permission of Met Trans A (Ref 28)

\section{Fabrication of Oxygenated Copper Components by EBM}

In the atomization of copper by rapid solidification processing, similar to that for the superalloys shown in Fig. 4, the affinity of copper for oxygen is often so great, that even under the most stringent inert environments, the copper particles will include some oxygen. This can allow for the formation of copper oxides (especially $\mathrm{Cu}_{2} \mathrm{O}$ ) or retention of interstitial oxygen which will form $\mathrm{Cu}_{2} \mathrm{O}$ during $\mathrm{EBM}$ fabrication. Ramirez et al. [30] have shown that EBM fabrication of products utilizing $\mathrm{Cu}$ powder (containing $<1$ wt. $\%$ oxygen) will create directional $\mathrm{Cu}_{2} \mathrm{O}$ columns or precipitate architectures similar to those shown for Co-base alloy in Fig. 5 and Ni-base alloy in Fig. 14. These features are illustrated for comparison in Fig. 21 which shows long precipitate $\left(\mathrm{Cu}_{2} \mathrm{O}\right)$ columns at the left of the facing vertical plane, and more cellular precipitate structures dominating

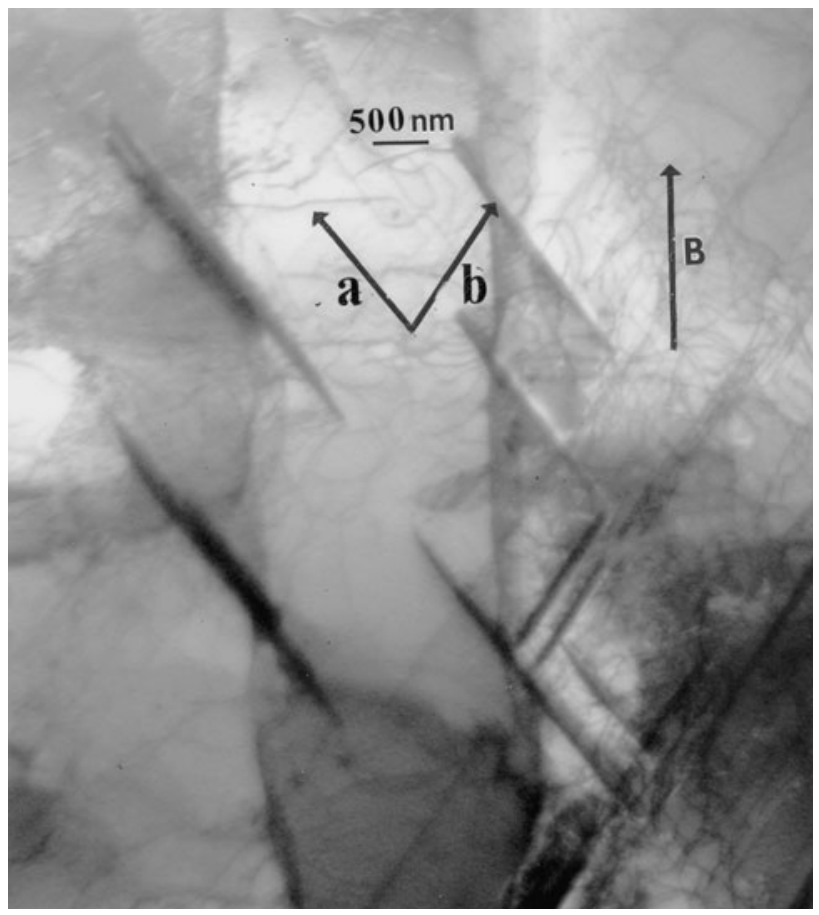

Fig. 17 TEM bright-field image for $\mathrm{Ni}_{3} \mathrm{Nb}$ precipitate platelets in Figs. 15 and 16. The crystallographic coincidence is illustrated by directions $a$ and $b$ as in Fig. 16. The specimen was prepared by electroetching in a $20 \%$ perchloric- $80 \%$ methanol solution at $13 \mathrm{~V}$ and $\sim 29^{\circ} \mathrm{C}$. Notice dislocations associated with the precipitates. $B$ indicates build direction. Used by permission of Met Trans A (Ref 28)

the microstructural architecture. However, as in the case of the superalloy precipitate architectures in Figs. 5 and 14, Fig. 21 illustrates that the precipitate column spacing is also essentially the same $(\sim 2 \mu \mathrm{m})$ as a consequence of the same electron beam scan strategy or scan parameters in the EBM fabrication process.

Figure 22(a) illustrates the $\mathrm{Cu}_{2} \mathrm{O}$ cubic structure ( $a=4.3 \AA$ ) while Fig. 22(b) shows an XRD spectrum representing the EBM-fabricated microstructural architecture shown in Fig. 21. The enlarged inset highlights the $\mathrm{Cu}_{2} \mathrm{O}$ (111) reflection peak, and the $\mathrm{Cu}_{2} \mathrm{O}$ peak fraction in Fig. 22(b) represents $\sim 2$ vol.\%.

It is well known that copper oxides (both $\mathrm{CuO}$ and $\mathrm{Cu}_{2} \mathrm{O}$ ) are readily dissolved by acids, and acid etching of the microstructure in Fig. 21 produces systematic etch pits which emulate the cubic structure of $\mathrm{Cu}_{2} \mathrm{O}$. This is illustrated in the SEM views in Figs. 23 and 24 representing the vertical and horizontal image planes in Fig. 21, respectively. Many square or orthogonal pits are evident in both SEM views (Fig. 23 and inset in Fig. 24). It is readily 


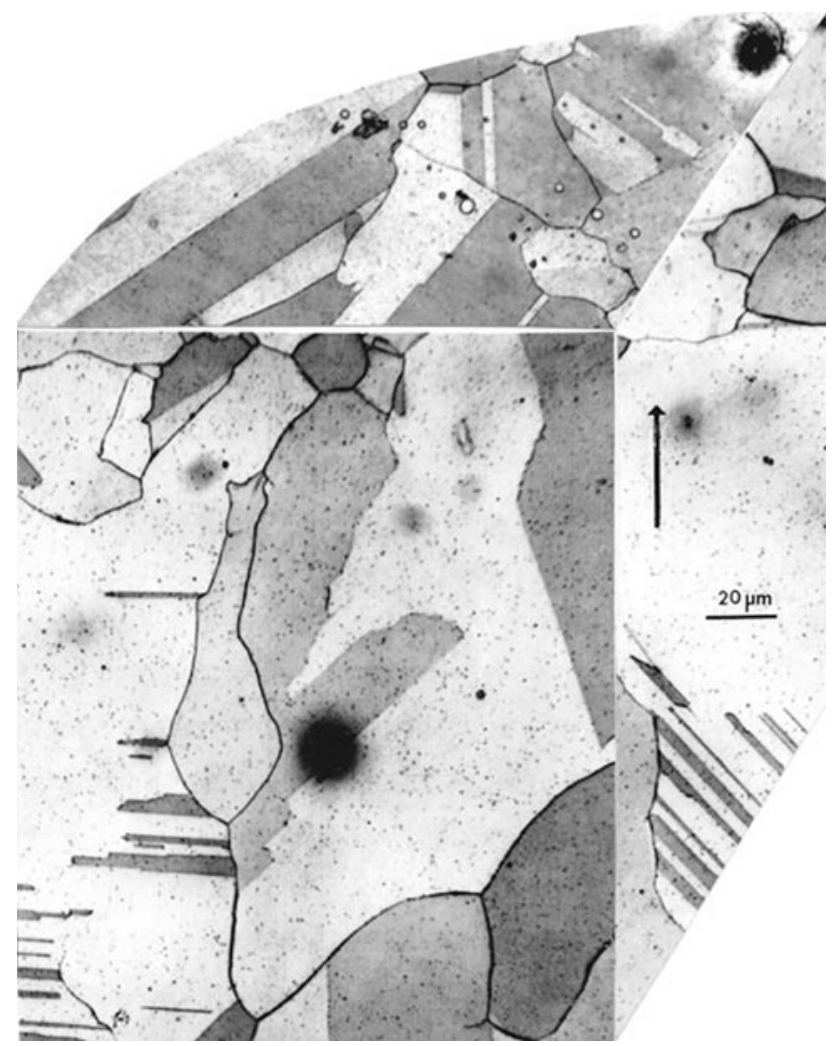

Fig. 18 3D-LM image composite representing the HIP-annealed EBM fabricated Ni-Cr-Mo-Nb alloy for comparison with Fig. 14. Notice exaggerated etching at straight, coherent $\{111\}$ boundaries. Large arrow represents the build direction. Used by permission of Met Trans A (Ref 28)

apparent in Fig. 25 that the structural or microstructural detail provided by the etchant, as in many metallographic etchants (Figs. 5, 14, for example), results from localized reactions either of the microstructural phase (such as the $\mathrm{Cu}_{2} \mathrm{O}$ ) or reactions with the area surrounding the phase as a result of elemental depletion to satisfy the phase composition. Such is the case for the $\mathrm{Cr}_{23} \mathrm{C}_{6}$ precipitates in Figs. 6 to 8 and 10 (b) where $\mathrm{Cr}$ depletion occurs, as well as the $\mathrm{Nb}_{3} \mathrm{Cr}$ and $\mathrm{NbCr}_{2}$ precipitates in Figs. 14 to 16, 18, and 19. In many respects, these features are etching artifacts which render the corresponding microstructural features in the image.

Figure 25 shows a magnified, isometric image reconstruction showing cellular and columnar $\mathrm{Cu}_{2} \mathrm{O}$ precipitate architectures, while Fig. 26 shows a corresponding TEM bright-field image, in the plane parallel to the build direction for the $\mathrm{Cu}_{2} \mathrm{O}$ precipitate cell-like microstructures. Figure 26 shows the $\mathrm{Cu}_{2} \mathrm{O}$ precipitates to have average sizes between about 50 and $100 \mathrm{~nm}$. In some regions these precipitates are engulfed in dense dislocation arrays,

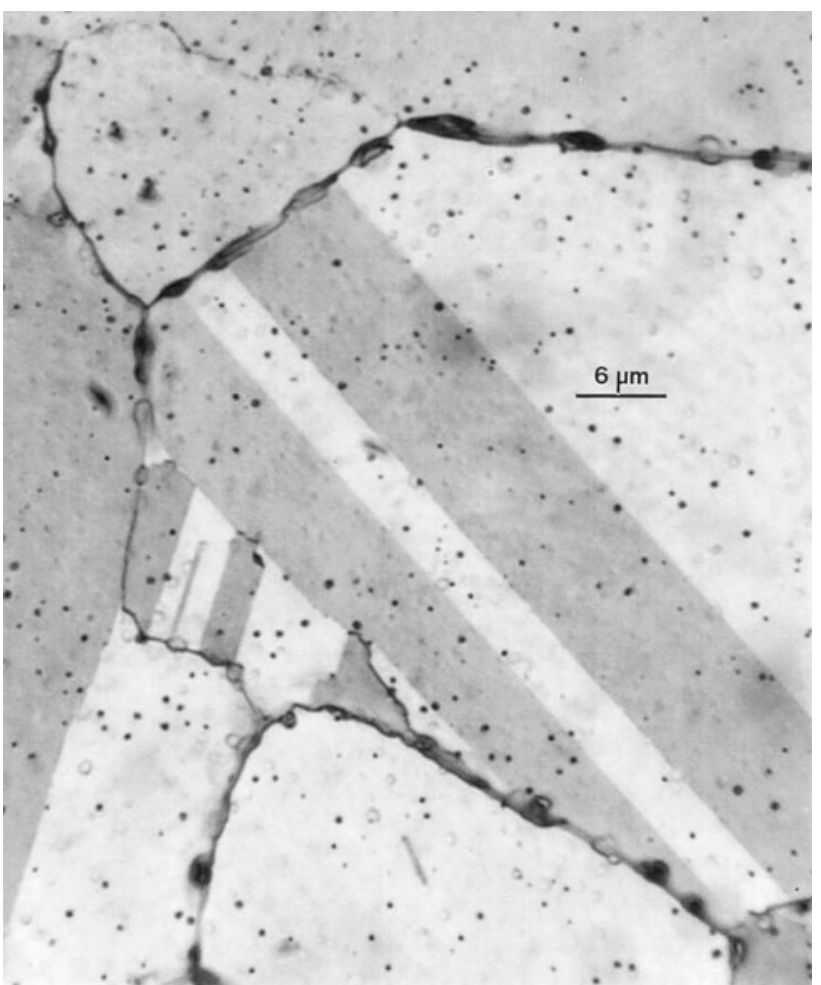

Fig. 19 Magnified light microscope (LM) image in the vertical plane parallel to the build direction as in Fig. 18 showing globular grain boundary and matrix precipitates. Notice the absence of precipitates on the coherent twin boundaries

possibly generated as a consequence of thermal stresses during the precipitation and rapid cooling as the component is fabricated by EBM. These features are somewhat more discernable in the TEM image in the corresponding horizontal plane in Fig. 25 as shown in Fig. 27, and in particular the magnified inset in Fig. 27. The arrows in the inset in Fig. 27 illustrate selective etching of the $\mathrm{Cu}_{2} \mathrm{O}$ precipitate particles which, in the LM images are systematically linked to form large etch pits often exhibiting the cubic or cube-related geometry as shown in the SEM images of Fig. 23 and the inset in Fig. 24. The inset in Fig. 27 also shows the details of the dislocation interactions with the $\mathrm{Cu}_{2} \mathrm{O}$ precipitates forming continuous networks of precipitates and connecting dislocations. TEM electroetching utilized a solution of $825 \mathrm{~mL}$ water, $375 \mathrm{~mL}$ ethanol, $300 \mathrm{~mL}$ phosphoric acid, $75 \mathrm{~mL}$ propanol, and $2.5 \mathrm{~g}$ urea; in contrast to a solution of $100 \mathrm{~mL}$ water, $8 \mathrm{~mL}$ sulfuric acid, $4 \mathrm{~mL}$ sodium chloride, and $2 \mathrm{~g}$ of potassium perchlorate for LM etching as described in more detail in Ramirez et al. [30]. 


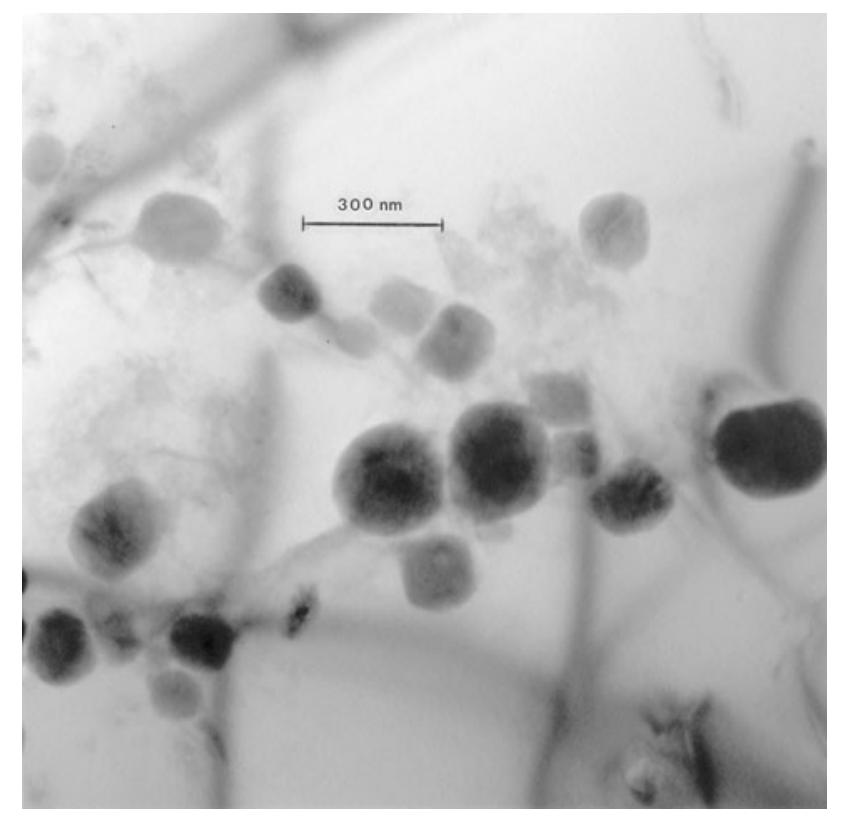

Fig. 20 TEM bright-field image showing $\mathrm{NbCr}_{2}$ laves precipitates as in Fig. 19

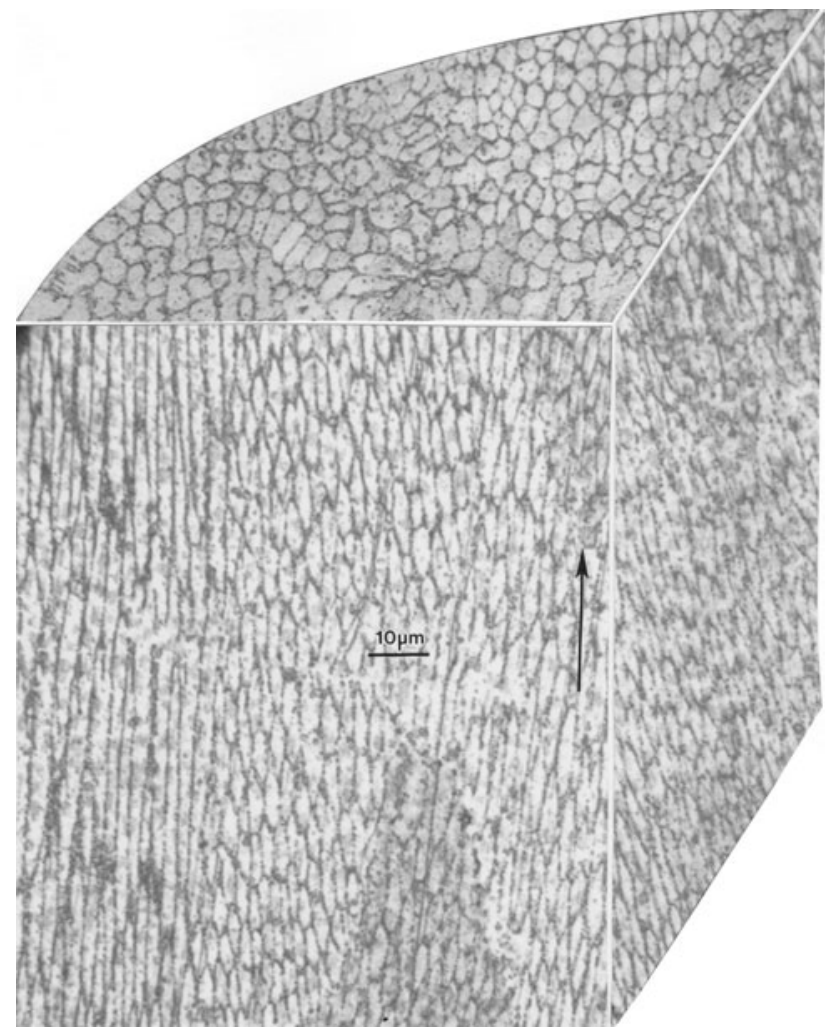

Fig. 21 3D-LM image composite showing columnar and cellular precipitates $\left(\mathrm{Cu}_{2} \mathrm{O}\right)$ architecture representing and EBM cylindrical component of $\mathrm{Cu}$. The arrow shows the EBM build direction parallel to the cylinder axis. Etchant: $100 \mathrm{~mL} \mathrm{H}_{2} \mathrm{O}, 8 \mathrm{~mL} \mathrm{H}_{2} \mathrm{SO}_{4}, 4 \mathrm{~mL}$ saturated $\mathrm{NaCl}$ solution
A
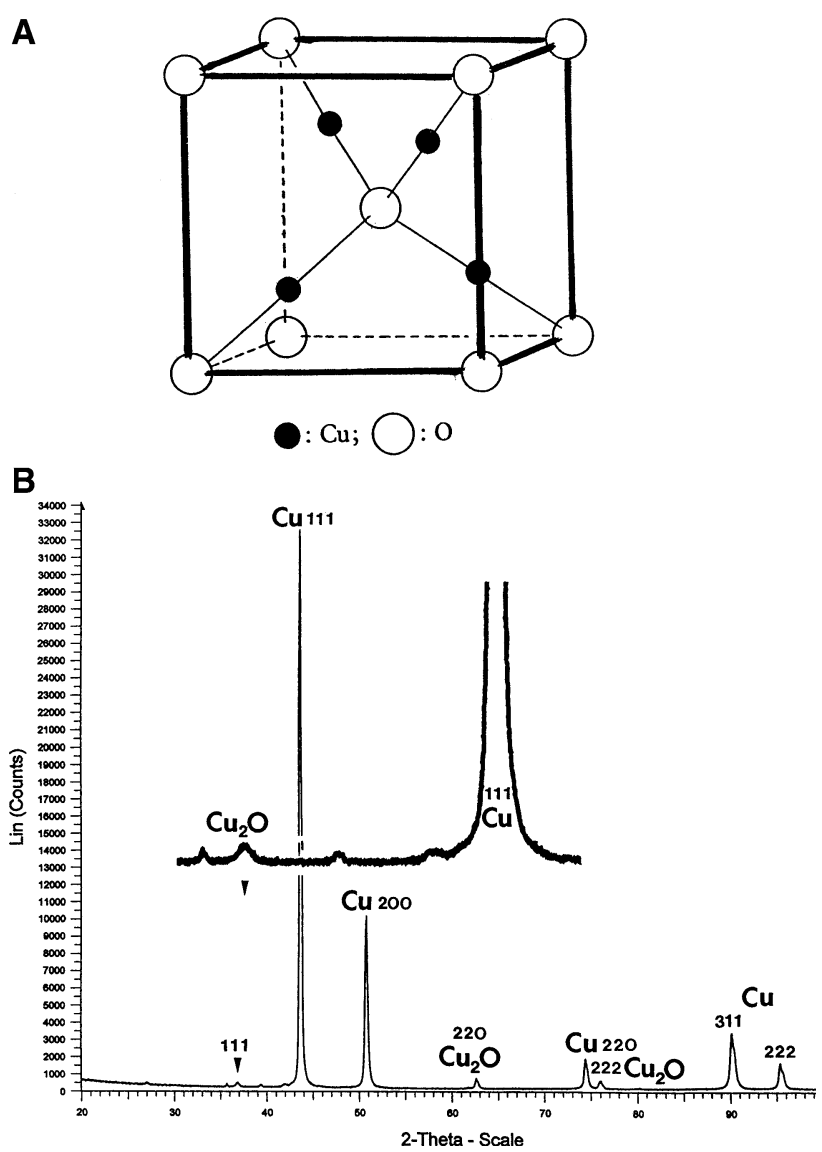

Fig. 22 a $\mathrm{Cu}_{2} \mathrm{O}$ cubic crystal unit cell. b XRD spectrum for the $\mathrm{Cu}_{2} \mathrm{O}$ precipitates in the EBM fabricated $\mathrm{Cu}$ cylinder in Fig. 21. The inset shows the $\mathrm{Cu}_{2} \mathrm{O}$ (111) peak (arrows)

It is of interest to observe that the etching at individual $\mathrm{Cu}_{2} \mathrm{O}$ precipitates in the inset in Fig. 27 represents a much smaller scale of etching than the chemical etching occurring for the LM samples as represented in more detail in the SEM images of Fig. 23 and the inset in Fig. 24. This represents the refinement of electroetching in the polishing plateau for the preparation of TEM specimens in contrast to the LM etching to produce image contrast in the light microscope.

\section{Discussion and Closure}

We have noted in some of the discussion above, in the context of specific applications of light microscopy for the characterization of microstructural/precipitation architectures for EBM-fabricated components, the unique diagnostic attributes (especially visual) of LM/metallography. While instrumentation innovations have occurred over the years since the work of Sorby [19], the quality of images in 

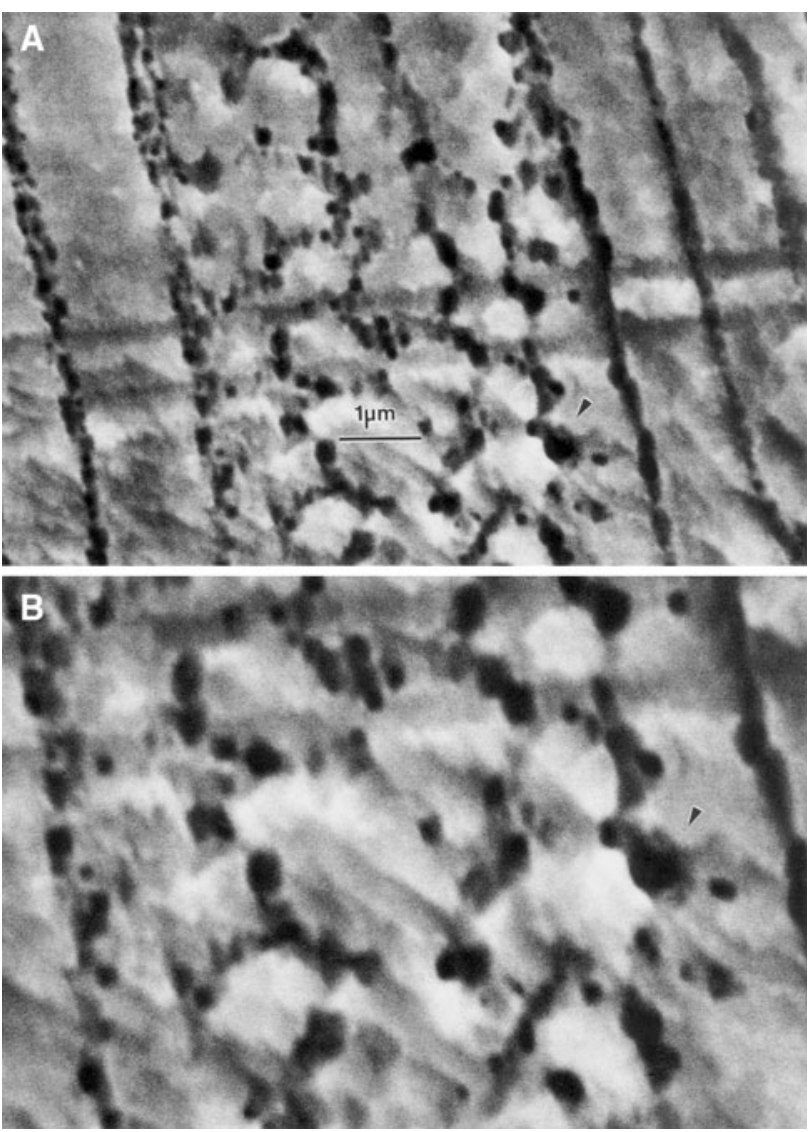

Fig. 23 SEM image views in the vertical plane for the composite shown in Fig. 21. The arrow shows a reference feature in both images

many cases have not changed significantly. Of course this is also true of TEM imaging which has demonstrated very unique diagnostic features of materials microstructures, especially in the submicron (nano) size regime, which permits the direct observation of dislocations and other related microstructural features. For example, compare Figs. 8 and 9 for Co-base alloy fabrication; Figs. 15 and 17 for Ni-base alloy fabrication; and Figs. 25 and 26 for the oxygenated $\mathrm{Cu}$ EBM fabrication in this study. In fact, and in contrast to these present observations relating the "new directional solidification" using EBM, the original directional solidification studies (including unidirectional eutectic solidification as represented in Fig. 2) involved similar combinations of light and electron microscopies $[20,31]$. Moreover, modern materials characterization has

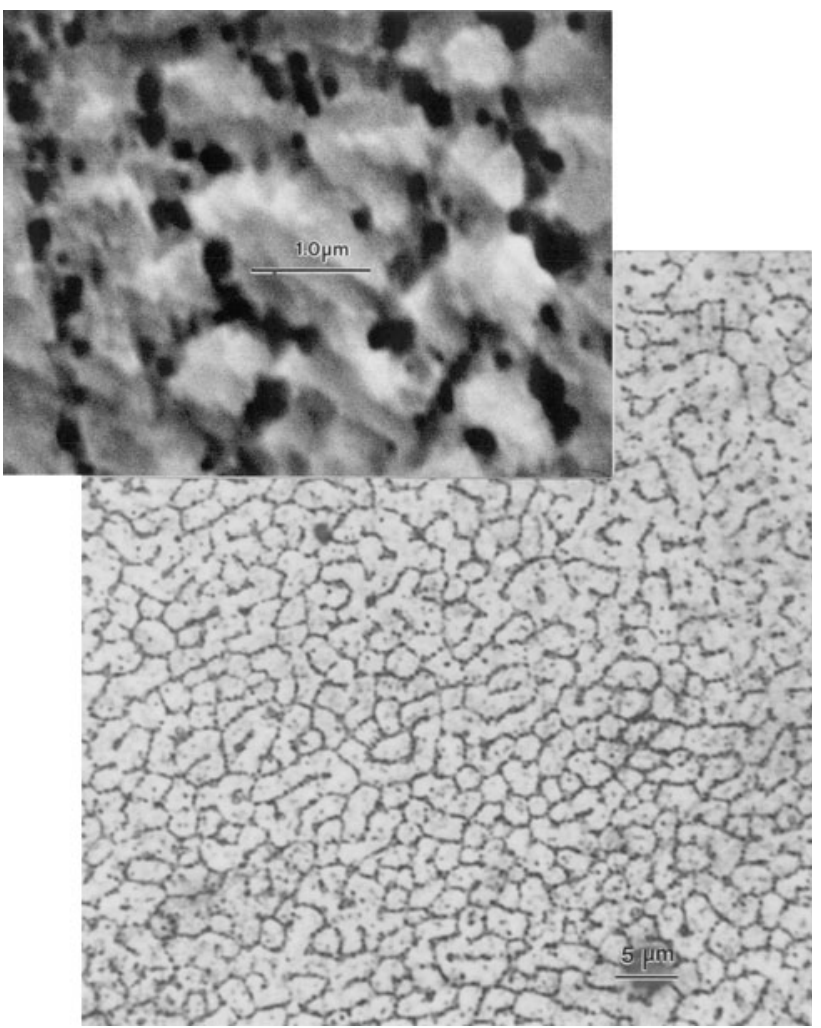

Fig. 24 SEM image inset in the horizontal (surface) plane in Fig. 21 showing etching details for the cellular columns composed of $\mathrm{Cu}_{2} \mathrm{O}$ precipitates. After Ramirez et al. [30]

involved combinations of macro-, micro-, and nano-imaging, including elemental and crystallographic analysis at these scales $[22,32]$. We have not included these specific analytical components in any rigorous diagnostic studies in this presentation. However, these analyses are apparent from the supporting literature [21, 23, 28, 30].

It can be concluded from this study that LM will continue to provide a fundamental overview of understanding for evolving new technology, particularly advanced manufacturing technology, which has a metallurgical basis. Just as LM has served metallurgy in its broadest context since the time of Sorby [19], it will continue to provide visual comparisons and understanding of materials and especially metallic microstructures and microstructural architectures well into the future. 


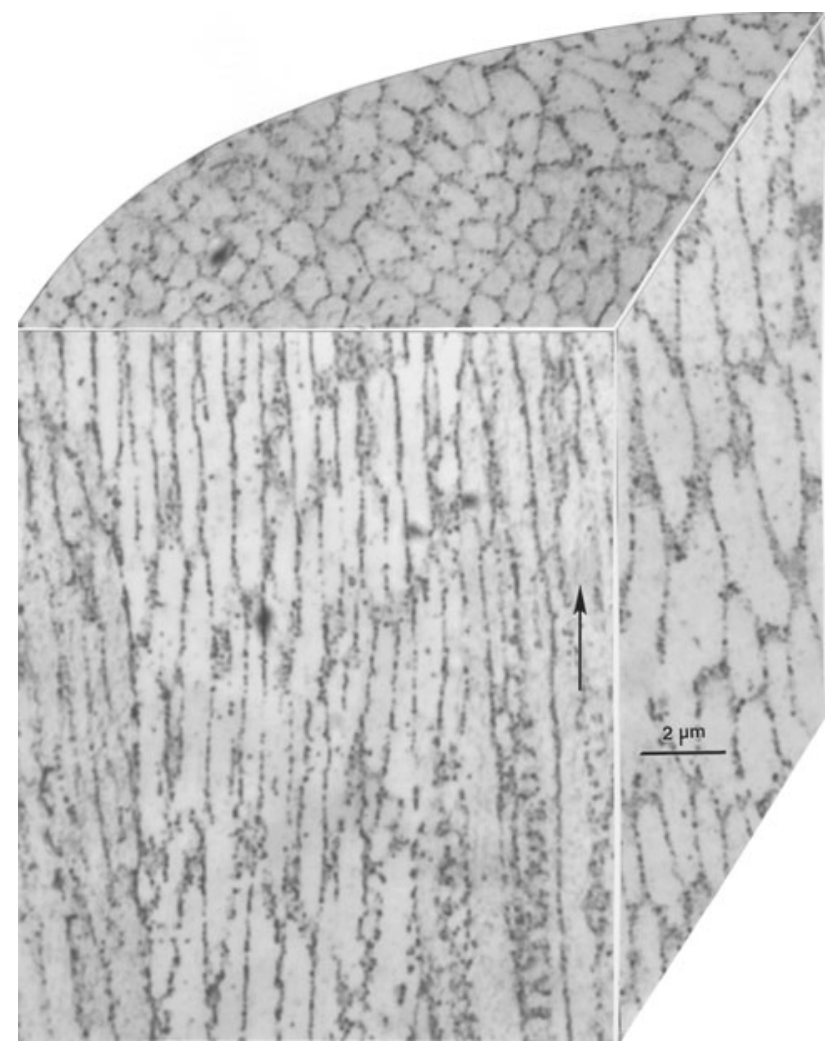

Fig. 25 Magnified 3D-LM composite for $\mathrm{Cu}_{2} \mathrm{O}$ precipitate columnar and cellular architecture in EBM fabricated $\mathrm{Cu}$ cylinder. The arrow represents the EBM build direction. After Ramirez et al. [30]

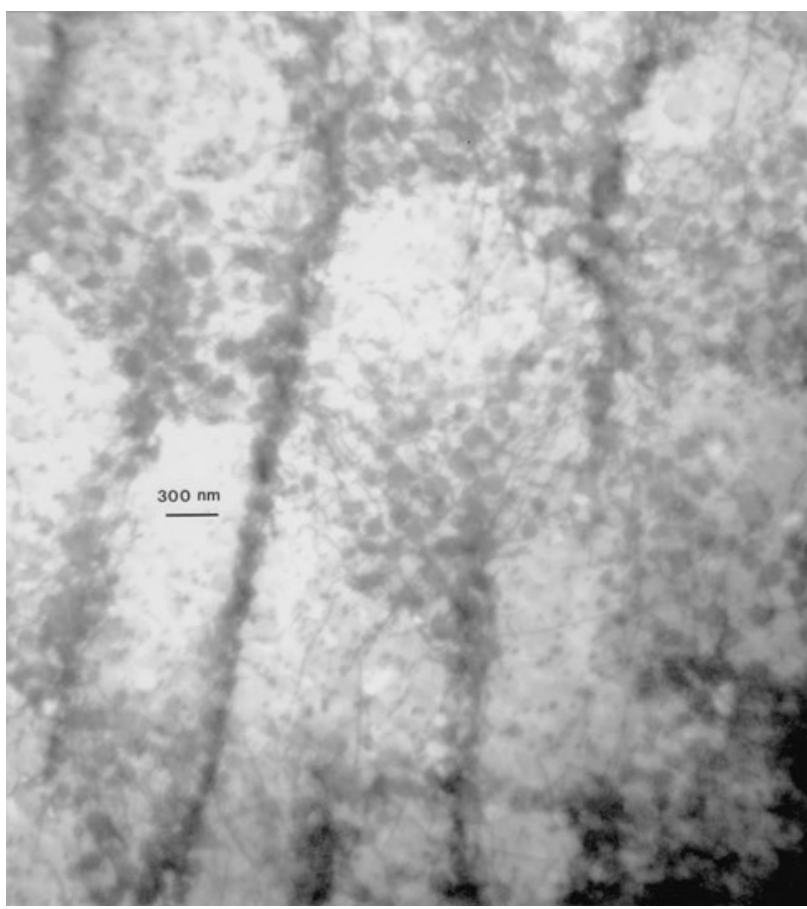

Fig. 26 TEM bright-field image in the vertical plane corresponding to the 3D-LM composite in Fig. 25

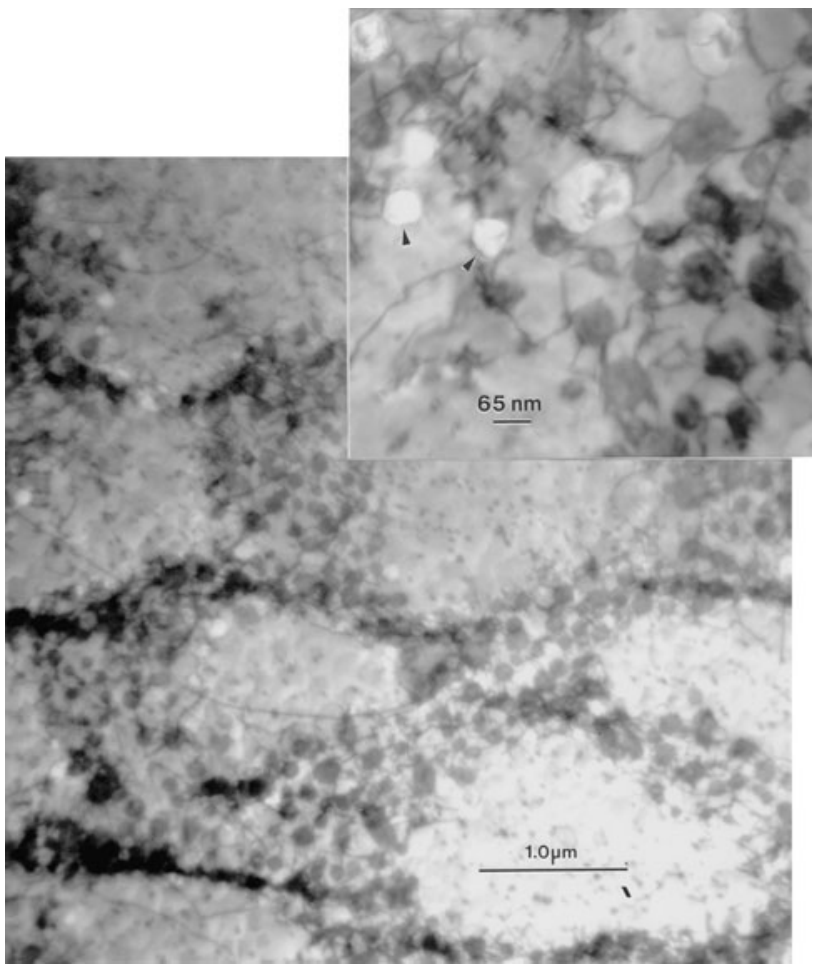

Fig. 27 TEM bright-field image in the horizontal plane corresponding to the 3D-LM composite in Fig. 25. The inset shows the details of the $\mathrm{Cu}_{2} \mathrm{O}$ precipitate-dislocation interaction. The arrows illustrate $\mathrm{Cu}_{2} \mathrm{O}$ precipitate dissolution. After Ramirez et al. [30]

Acknowledgments This work was supported in part by a Mr. and Mrs. MacIntosh Murchison Endowed Chair at The University of Texas at El Paso (UTEP). We also acknowledge partial support provided by the UTEP multidisciplinary materials science and engineering Ph.D. program, through the College of Engineering, for graduate assistantships. We are grateful to Frank Medina for his help in the fabrication of specimens by electron beam melting, and Dr. Ryan Wicker for the provision of experimental EBM facilities and support.

\section{References}

1. J. Czochralski, Ein neues Verfahren Zur messung des Kristallisation geschaindiglleit der metalle. Z. Phys. Chem. 92, 219-221 (1918)

2. P.W. Bridgman, Certain physical properties of single crystals of tungsten, antimony, bismuth, tellurium, cadmium, zinc and tin. Proc. Am. Acad. Arts Sci. 62, 305-310 (1925)

3. B. Chalmers, The Principles of Solidification (Wiley, New York, 1964)

4. H.S. Peiser (ed.), Crystal Growth (Pergamon Press, Oxford, 1967)

5. A.R. Ubbelohde, Melting and Crystal Structures (Pergamon Press, Oxford, 1965)

6. K. Nassau, Dr.: A. V. L. Verneuil: The man and the method. J. Cryst. Growth 13/14, 12-15 (1972)

7. M.C. Flemings, Solidification Processing (McGraw-Hill, New York, 1974)

8. D.M. Stefanescu, Science and Engineering of Casting Solidification, 2nd edn. (Springer, New York, 2008) 
9. J. Lacaze, A. Hazotle, Directionally solidified materials: Nickelbase supealloys for gas turbines. Textures Microstruct. 13(1), 1-11 (1990)

10. A. Ludwig (ed.), Solidification of Melts in Research and Technology (Wiley-VCH, Weinheim, 1999)

11. R. Mehrabian (ed.), Rapid Solidification Processing: Principles and Technologies III (National Bureau of Standards, Washington, DC, 1983)

12. N.J. Grant, in Industrial Materials Science and Engineering, Chap. 8, ed. by L.E. Murr (Mancel Dekker, Inc, New York, 1984), p. 243

13. K.A. Jackson, J.D. Hunt, Transparent compounds that freeze like metals. Acta Metall. 13, 1212-1215 (1965)

14. W.A. Tiller, Liquid Metals and Solidification (ASM, Cleveland, 1958), p. 276

15. F.D. Lemkey, E.R. Thompson (eds.), Conference on In-Situ Composites, NMAB 308 I, II, III (Printing and Publishing Office, National Academy of Sciences, Washington, DC, 1978)

16. R.C. Reed, The Superalloys: Fundamentals and Applications (Cambridge University Press, Cambridge, 2006)

17. E.R. Thompson, F.D. Lemkey, Directionally solidified eutectic superalloys, in Composite Materials, vol. 4, ed. by L.J. Broutman, R.H.. Krock (Academic Press, New York, 1974), pp. 101-110

18. F.D. Lemkey, H.E. Cline, M. McLean (eds.), In-Situ Composites IV (Elsevier, New York, 1982)

19. H.C. Sorby, The microscopic structure of steel. J. Iron Steel Inst. XXXI, 140-145 (1886)

20. R.W. Kraft, Solidification structures of eutectic alloys, in Metallography, Structures, and Phase Diagrams, Metals Handbook, vol. 8, 8 edn., ed. by T. Lyman (American Society for Metals, Materials Park, 1973), p. 155

21. L.E. Murr, E.V. Esquivel, S.A. Quinones, S.M. Gaytan, M.I. Lopez, E.Y. Martinez, F. Medina, D.H. Hernandez, E. Martinez, J.L. Martinez, S.W. Stafford, D.K. Brown, T. Hoppe, W. Meyers, U. Lindhe, R.B. Wicker, Microstructures and mechanical properties of electron beam-rapid manufactured $\mathrm{Ti}-6 \mathrm{Al}-4 \mathrm{~V}$ biomedical prototypes compared to wrought Ti-6Al-4V. Mater. Charact. 60, 96-105 (2009)

22. L.E. Murr, Electron and Ion Microscopy and Microanalysis: Fundamentals and Applications, 2nd edn. (Marcel Dekker, Inc., New York, 1990)
23. S.M. Gaytan, L.E. Murr, E. Martinez, J.L. Martinez, B.I. Machado, D.A. Ramirez, F. Medina, S. Collins, R.B. Wicker, Comparison of microstructures and mechanical properties of solid \& mesh cobalt-base alloy prototypes fabricated by electron beam melting. Metall. Mater. Trans. A 41A, 3216-3225 (2010)

24. L. Thijs, F. Verhaeghe, T. Craeghs, J. Humbeeck, J.-P. Van Kruth, A study of the microstructural evolution during selective laser melting of Ti-6Al-4 V. Acta Mater. 58, 3303-3310 (2010)

25. L.E. Murr, Interfacial Phenomena in Metals and Alloys (Addison-Wesley Publishing Co., Reading, 1975). (also reprinted in 1990 by Techbooks, Herndon, Va; Currently available from CBLS, CBLS.com)

26. E.A. Trillo, L.E. Murr, Effects of carbon content, deformation and interfacial energies on carbide precipitation and corrosion sensitization in 307 stainless steel. Acta Mater. 47(1), 235-245 (1999)

27. M.A. Meyers, R.B. Gupta, L.E. Murr, Shock-wave consolidation of rapidly-solidified superalloy powders. J. Met. 33(10), 34-39 (1981)

28. L.E. Murr, E. Martinez, S.M. Gaytan, D.A. Ramirez, B.I. Machado, P.W. Shindo, J.L. Martinez, F. Medina, J. Wooten, D. Ciscel, U. Ackelid, R.B. Wicker, Microstructural architecture, microstructures, and mechanical properties for a nickel-base superalloy fabricated by electron beam melting. Metall. Mater. Trans. 42A, 349-3508 (2011)

29. Ch. Radakrishna, K.P. Pao, S. Srihivas, Laves phase in electron beam melted Inconel 718 J. Mater. Sci. Lett. 14, 1810-1812 (1995)

30. D.A. Ramirez, L.E. Murr, E. Martinez, D.H. Hernandez, J.L. Martinez, B.I. Machado, F. Medina, P. Frigola, R.B. Wicker, Novel precipitate-microstructural, architecture developed in the fabrication of solid copper components by additive manufacturing using electron beam welding. Acta Mater. 59, 4088-4099 (2011)

31. B.H. Kear, Advanced metal. Sci. Am. 255, 159-167 (1986)

32. L.E. Murr, Imaging systems and materials characterization. Mater. Charact. 60, 397-414 (2009) 